\title{
Cuatro grandes proyectos urbanos: una reinterpretación de la gestión desde el diseño urbano para la construcción de lugar
}

Four major urban projects: a reinterpretation of the urban management from design to construction site

Mario Torres Jofré y Andrea Woerner Rudloff

\section{Filiación}

Académico de la F.A.U. de la Universidad de Chile mtorres@uchilefau.cl

\section{Resumen}

Se presenta cuatro grandes proyectos urbanos planeados desde el diseño urbano, en cuanto disciplina que contribuye a la construcción de imagen, identidad y lugar; se trata de la reinterpretación de la gestión a partir del proyecto urbano. Es un artículo fundado en la experiencia acumulada en un quehacer académico y profesional en la elaboración de grandes proyectos urbanos; es decir, se basa tanto en la conceptualización como en la praxis.

Palabras clave

Diseño Urbano; la gestión a partir del proyecto.

\begin{abstract}
This article features four major urban projects that started as Urban Design projects. Urban Design is understood as a discipline that contributes to the construction of an image, identity and place. The author comes from an academic and professional background, and has participated in the design of major urban projects, thus presenting his views from both a conceptual and practical standings.
\end{abstract}

\section{Key words}

Urban design; Management from urban design.

\section{Sumario}

Introducción

Principios proyectuales

Ideas urbanas para Santo Domingo

Anillo interior de Santiago

Plan Maestro Anillo Interior de Santiago - Segmento D

Plan Maestro y Seccional Maestranza San Eugenio

Concurso Internacional de Ideas Av. Vitacura Oriente

Conclusión

Bibliografía

Anexo: Equipos de profesionales por proyecto 


\section{Introducción}

En nuestro país, la preparación para la celebración del Bicentenario de la República, en especial, las obras conmemorativas, ha instalado en la discusión urbana la relevancia de los denominados grandes proyectos urbanos como factor de desarrollo de las ciudades. Una temática nada reciente en el ámbito internacional, particularmente en varios países europeos. En ellos, adicionalmente a la caracterización de los efectos generados por las intervenciones, se ha profundizado en la investigación sobre la gestión de los mismos y los impactos en la valoración del suelo urbano. Sin embargo, desde la óptica del proceso proyectual, no se ha conceptualizado suficientemente, en la importancia de éstos en la construcción de imagen urbana, identidad y lugar.

Este artículo presenta cuatro grandes proyectos urbanos planeados desde el diseño urbano, en cuanto disciplina que contribuye a la construcción de imagen, identidad y lugar; se trata de la reinterpretación de la gestión a partir del proyecto urbano. Es un artículo fundado en la experiencia acumulada en nuestro quehacer académico y profesional en la elaboración de grandes proyectos urbanos; es decir, se basa tanto en la conceptualización como en la praxis.

Praxis orientada por el sentido ético del proyecto, especialmente, porque entendemos que sus efectos repercuten sobre la sociedad en su conjunto $y$, en ellos, se ha buscado siempre maximizar la rentabilidad social de la intervención, pensando que detrás de todo proyecto urbano existe una propuesta de vida.

En los últimos cuatro años nos ha correspondido desarrollar igual número de propuestas de grandes proyectos urbanos, dos se han desarrollado bajo el alero de esta Facultad y dos bajo el alero de nuestro estudio privado. No se trata de cuatro miradas diferentes, por el contrario, son cuatro propuestas de principios proyectuales similares con acento en el diseño urbano, como forma de reinterpretación de la gestión urbana. Son cuatro operaciones tendientes a maximizar la rentabilidad social, radicada en la generosidad del espacio público generado, para la construcción de civilidad y de lugar. Tres localizados en Santiago de Chile y, uno, en Santo Domingo, República Dominicana. Presentamos una gran operación urbana -que es canalizada a través del Directorio Ejecutivo de Obras Bicentenario (DEOB)-, el proyecto Anillo Interior de Santiago; si bien referimos una sola operación urbana, se trata de dos planes: Plan Maestro Anillo Interior de Santiago Segmento D y Plan Maestro Maestranza de San Eugenio. Además, el Plan Maestro para Villa Mella, en el contexto de Ideas Urbanas para Santo Domingo, y la propuesta al Concurso Internacional de Ideas Av. Vitacura Oriente.

Al pensar en el cómo dar respuesta a un encargo, para recuperar parte del tejido urbano de una ciudad consolidada o en vías de consolidación, se nos plantea siempre la disyuntiva moral respecto del tipo de actuación que debiéramos proponer, independiente si se trata de ideas, anteproyectos o proyectos. El proceso metodológico para la elaboración de las propuestas urbanas -que hemos empleado- nace del reconocimiento de la historia y de las características estructurales y perceptuales de la ciudad en la cual vamos a intervenir, dado que el tejido urbano -en nuestra opiniónno es otra cosa que el producto de la sumatoria de las relaciones humanas o sociales, físicas y económicas que se dan sobre un territorio determinado. Más aún, el tejido 
urbano es una representación de las características de la sociedad. Así, la propuesta urbana posee el sustento ético, que a fuerza de ingenio y meditación posibilita crear una arquitectura urbana, para la ciudad que habitan millares de personas, que peregrinan en búsqueda de felicidad.

\section{Principios proyectuales}

Al observar la marcha del crecimiento urbano de nuestras ciudades, guiada por principios básicos de mercadeo más que por procesos de planificación y construcción de lugares para la vida del ser humano; cuando el mercado por medio de la publicidad, nos pretende hacer creer que el Edén está al alcance de nuestras manos y que la oferta de los productos inmobiliarios actuales nos reportará la adecuada calidad de vida que anhelamos; cuando la ciudad se presenta cada vez más como un ambiente propicio para el anonimato y la soledad; cuando so pretexto de diversa índole, la ciudad, se transforma en laboratorio de múltiples experiencias e informaciones de disímil signo; entendemos que el proyecto urbano precisa retomar su base conceptual por esencia. El proyecto urbano debe volver a la base conceptual centrada en las necesidades del ser humano, necesidades materiales y espirituales. El proyecto urbano debe volver a su sustento teleológico, es decir, a su fundamento en los fines últimos de la sociedad, que radica en la adecuada concepción del bien común como principio rector.

En este orden de ideas, no sin dificultades, se concibe el proyecto urbano desde el diseño urbano como disciplina, que adicionalmente a concebirse como «El acertado juego de relaciones espaciales que se produce entre los elementos volumétricos, edificios $u$ otros, entre estos volúmenes y los espacios exteriores que delimitan y, por último, entre sus espacios exteriores entre sí» (López, J; 1999, 21), debe intentar dar respuesta a las exigencias inmateriales del ser humano en la ciudad, línea que desde la década de los '80, ha sido recogida en todos los trabajos sobre planificación de la imagen urbana efectuados bajo el alero del Departamento de Urbanismo de la Facultad de Arquitectura de la Universidad de Chile, con la participación destacada en ellos de Michael Trieb, Manuel Fernández, Martín Durán y, Pablo De La Llera.

La base conceptual desde el diseño urbano, utilizada en los proyectos que se presentan en este artículo, pone énfasis en la tarea de reconocer las exigencias psicológicas y espirituales que los hombres hacen al medio ambiente construido, representarlas y procurar su valoración, asociado a las exigencias sociales, económicas, políticas, jurídicas, ecológicas y técnicas. Para la gestión, el diseño urbano, no se concibe como una interfaz entre lo público y lo privado, sino como el sustento que permite dar coherencia al sistema de relaciones entre las diversas exigencias a la ciudad. Bajo esta concepción el diseño urbano es producto y proceso.

Carmona et al (2003), cuando establecen seis dimensiones en el proceso del diseño urbano, dimensiones que posibilitan la construcción de lugares públicos - espacios urbanos, están pensando tanto en el producto (el medio ambiente construido) como en el proceso por los cuales es producido. Ellos refieren a la dimensión: formal, perceptual, social, visual, funcional, y temporal, asociadas a la consideración del contexto global, local, de mercado y normativo que repercuten en el proyecto urbano a desarrollar. Son también Lynch, Appleyard, Jacobs, Rossi, Tibbalds, entre otros 
autores, los que desde su particular mirada e interpretación, dan fundamento a estas dimensiones del diseño urbano.

Los cuatro proyectos que se presentan, además de tener en consideración las dimensiones del diseño urbano, se basan en cuatro principios básicos a saber: a). tipo y metamorfosis, que implica reconocer aquellos tipos básicos que dan identidad y orientación al área de intervención $y$, a partir de ellos, generar su metamorfosis; b). unidad y multiplicidad, que reconoce funciones y actividades heterogéneas $y$, por ello, se precisa de una síntesis entre unidad y diversidad, aspecto que la estructura propuesta -en virtud de la imagen-objetivo y conceptual- debe facilitar; $c$ ). continuidad $y$ transformación, donde el deterioro producto de actividades incompatibles con la residencia y de la obsolescencia por cambio y crecimiento del tejido edificado, supone el necesario ajuste y equilibrio considerando los elementos trascendentes e identitarios; $y, d)$. lo general y lo particular, como principio al cual se subordinan los tres anteriores, de modo de reconocer lo especial o particular del área de intervención o renovación.

Para materializar las imagen-objetivo y conceptuales postuladas y posibilitar la integración de la gestión urbana al diseño urbano, se proponen proyectos estratégicos, que deben verse como intervenciones urbanas de efecto multiplicador, permitiendo proyectar una imagen positiva, capaz de atraer y captar capitales, porque se plantean como acciones generadoras de externalidades positivas. Los proyectos estratégicos deben mirarse como parte del plan general, donde los efectos se superponen y revalorizan entre sí, multiplicando sus externalidades positivas y resaltando las economías de escala.

\section{Ideas urbanas para Santo Domingo}

El programa Ideas Urbanas para Santo Domingo, realizado por el Ayuntamiento de esa ciudad y coordinado por la Oficina del Plan Director Urbano, convocó a un conjunto de 27 estudios de arquitectura de varios países americanos y europeos, entre los que se pueden destacar: Manuel Sola-Morales, Manuel Gallego, Henk Döll (Mecanoo), Clorinda Testa, entre otros.

Se invitó a los profesionales seleccionados a una reflexión propositiva sobre la ciudad de Santo Domingo, para un conjunto de emplazamientos, identificados como áreaproblema, pero de gran potencial urbanístico. Los resultados buscaban dotar y aportar en la concreción de una nueva imagen-objetivo para el Plan General de Ordenamiento Territorial. En la Figura No 1, es posible observar las 27 zonas de intervención en la ciudad de Santo Domingo. 


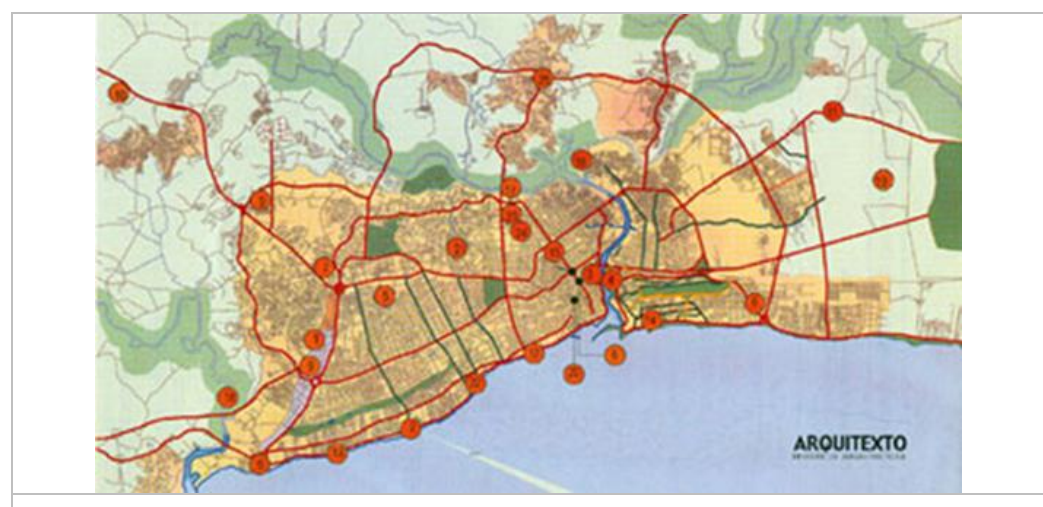

Fig.1.- Plano de la Ciudad de Santo Domingo con Identificación de las Zonas de Intervención

Las propuestas urbanas debían enmarcarse dentro de un marco de realismo y factibilidades técnico-económica, socialmente aceptables y rigurosas conceptualmente. Además, en el nivel exigido, suscitar el interés público y privado, nacional e internacional, para la materialización de proyectos capaces de revertir el proceso de deterioro y de pérdida de oportunidades.

Se buscaba un conjunto de proyectos urbanos -de diferentes escalas- que tuvieran la cualidad de estructurar el futuro desarrollo urbano de la ciudad. No se pretendió sustituir o suplir la elaboración de planes de ordenamiento urbano a diferentes escalas, por el contrario, que los planes -a partir de un adecuado proceso de reflexiónposibilitaran llevar adelante operaciones urbanas cuyo resultado fuese un «gran negocio» para los habitantes de Santo Domingo y se viese reflejado en las mejoras de la calidad de vida.

\section{Villa Mella - Un Centro para Santo Domingo Norte}

Nos correspondió elaborar la propuesta para el poblado de Villa Mella (Zona 25), asentamiento popular ubicado en la margen norte del río Isabela -periferia de la ciudad-, con crecimiento desproporcionado, no planificado, con la consecuente carencia de servicios y falta de articulación con el centro de la ciudad. 


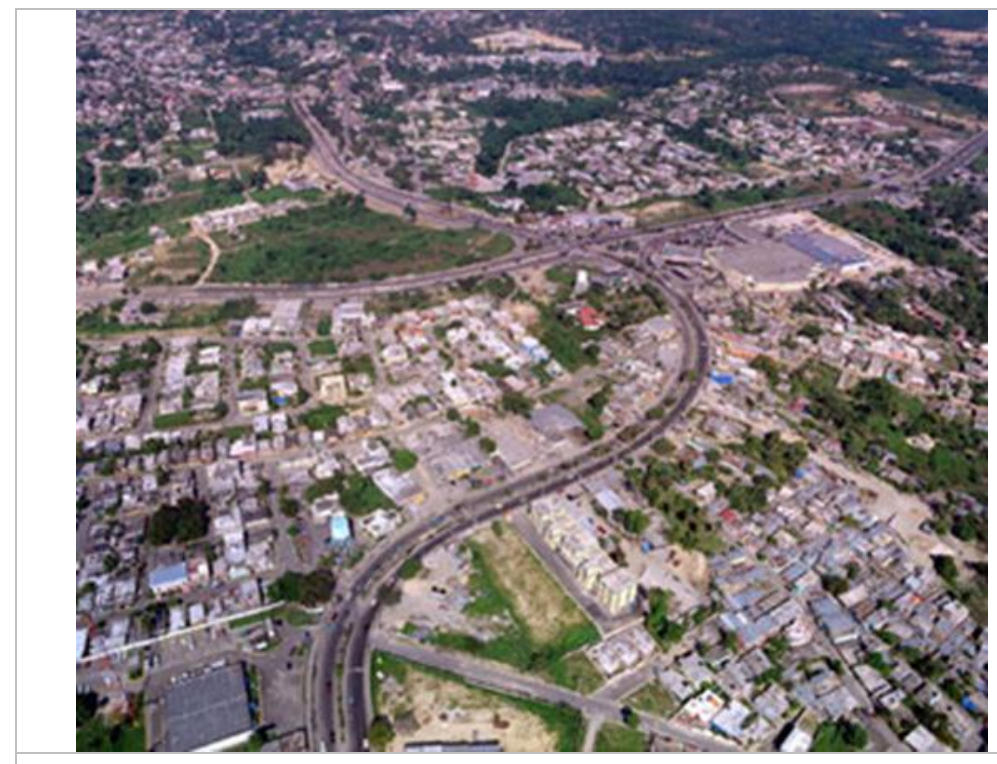

Fig.2.-Fotografía Aérea de la Zona de Actuación 25.

Las únicas vías de acceso a la zona de estudio es la Av. Máximo Gómez, que continúa en la Av. Hnas. Mirabal y la Av. Jacobo Majluta, es precisamente en esa intersección donde se emplaza la propuesta de intervención. La zona de estudio estuvo referida al tramo completo de la Av. Hnas. Mirabal, ya que, al funcionar como única vía conectora de un sinnúmero de urbanizaciones aisladas separadas por el río, sus afluentes y las zonas inundables; recreaba un panorama complejo sobre el cual era necesario establecer pautas para su ordenamiento.

La zona de intervención estaba conformada por el cruce de dos avenidas, una de penetración y otra de circunvalación, estructuradas por espacios consolidados de usos comerciales, que conforman un área de relevancia. Sin embargo, el asentamiento se encuentra desarticulado en sí mismo por la profusión de infraestructuras sin ninguna coherencia funcional. Existía un alto tráfico, generando por grandes flujos vehiculares y peatonales, factor que imprimía carácter a la zona y la identificaba como importante zona de confluencia y distribución.

Las exigencias establecidas para nuestro encargo, requerían un proyecto de reestructuración de un espacio con potencialidades de convertirse en centro urbano, reglamentando los modos de intervención y las estrategias de desarrollo que permitieran articular los usos residenciales del norte de la ciudad con las necesarias actividades comerciales, de servicios y equipamientos.

Para dar respuesta al objetivo general y a los específicos establecido por el Programa, se elabora un conjunto de acciones que la propuesta urbana debía considerar, entre ellas: a).- disminuir y eliminar los cruces vehiculares continuos, generadores de conflictos a lo largo de Av. Hnas. Mirabal; b).- dotar de espacios de uso público para los peatones y áreas de esparcimiento; c).- diversificar la utilización del suelo urbano; d). - dotar de un Centro de Intercambio Modal de Transporte; e).- crear un parque 
urbano; f).- recualificar el suelo y generar macromanzanas. A nivel conceptual, los objetivos se expresan en la estructuración observable en la Figura No 3.

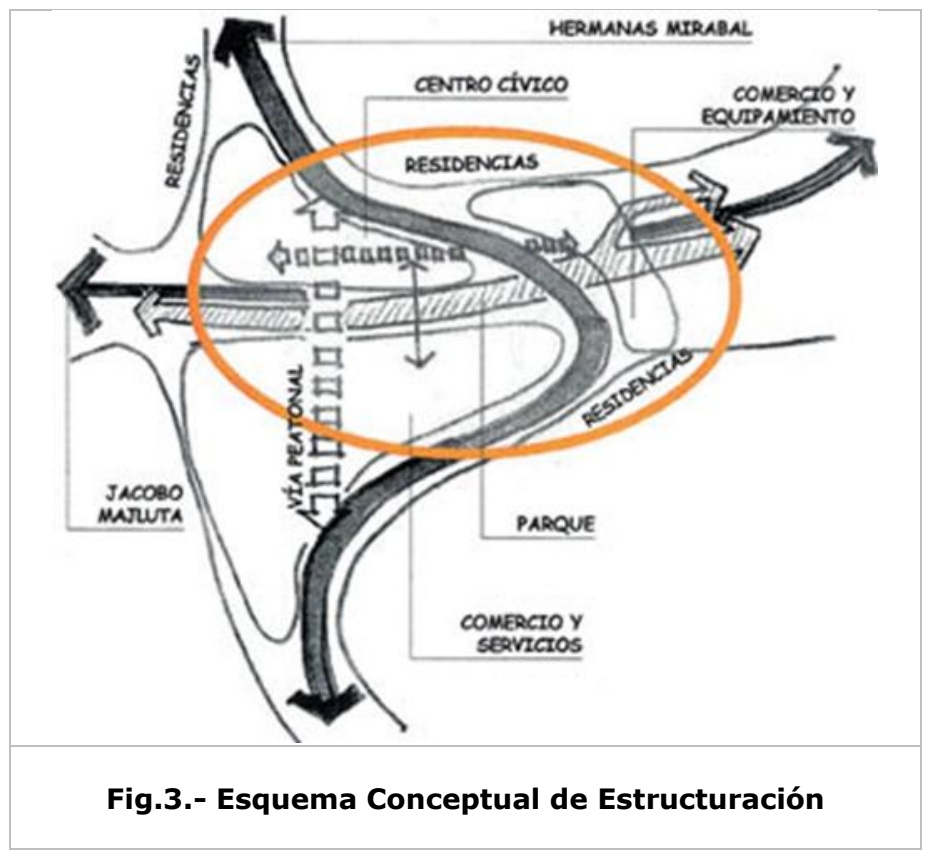

Un par de vías paralelas a Av. Hnas. Mirabal recoge los flujos vehiculares provenientes de las urbanizaciones existentes y los traslada sólo a tres nudos. Estas vías generan macromanzanas de usos eminentemente residenciales y la franja paralela a Av. Hnas. Mirabal se proyecta con una altura de edificación que posibilite la mezcla adecuada de usos, viabilizando la residencia con el comercio y los servicios.

La disminución de intersecciones conflictivas ordena el transporte público y otorga mayor fluidez al desplazamiento, se disminuyen los tiempos de viaje en las horas punta. La acción permite potenciar el dinamismo comercial de la vía que enlaza urbanizaciones aisladas y el centro de la ciudad, procurando evitar el conflicto entre las actividades residenciales y usos molestos.

El área de intervención específica alcanza a las 44,72 hectáreas, que corresponde a la zona aledaña a la intersección de las dos avenidas. Para recualificar la zona el diseño se orientó a la creación de «Un Centro para Santo Domingo Norte», aprovechando la coyuntura -en ese momento- de la división político-administrativa del Ayuntamiento de Santo Domingo. El Plan Maestro de ordenación del área de intervención se puede observar en la Figura No 4. 


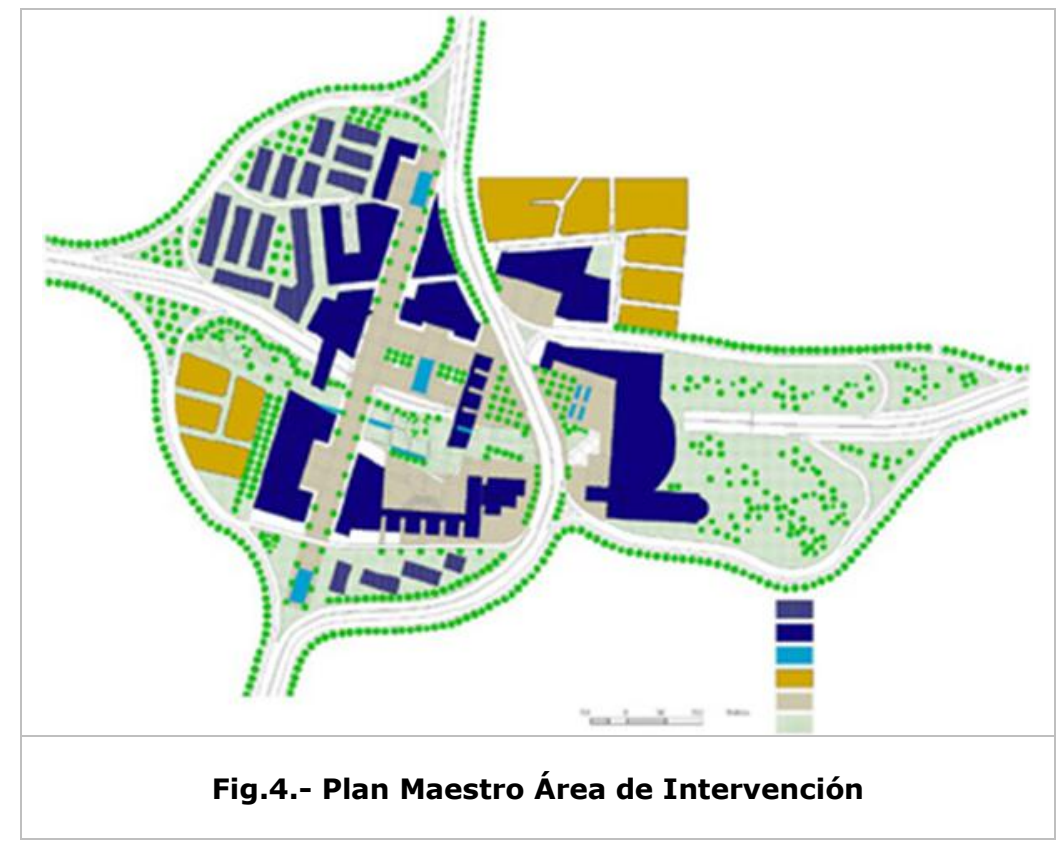

El centro se concibe capaz de contener la complejidad y variedad propia de la vida urbana, permitiendo la coexistencia de diversidad de culturas, contener las dotaciones necesarias para el desarrollo integral de la población y recoger los elementos de imagen e identidad local de manera de lograr el sentimiento de arraigo en los habitantes.

A fin de conseguir la recualificación general del área de estudio se propone una mayor densidad habitacional ( $15 \%$ de la superficie construida para viviendas) y constructibilidad (1,8 promedio para el área de intervención). Mas estos parámetros se compensan con bajas ocupaciones de suelo (22\%), así se permite aumentar las superficies destinadas a parques $\mathrm{y} / \mathrm{o}$ plazas públicas o semipúblicas incentivando la utilización del espacio urbano (27\%). La propuesta de superficie total construida a nivel de primera planta alcanza a los $98.765 \mathrm{~m}^{2}$, y la superficie total sobre el terreno natural, alcanza a los $605.925 \mathrm{~m}^{2}$.

Para evitar los conflictos y favorecer los cambios en el área de intervención, se propone una nueva estructuración de la vialidad, destinándose 10,19 hectáreas a espacios de circulación. Se eliminan los cruces conflictivos a nivel. La Av. Hnas. Mirabal se mantiene a nivel de superficie dado su carácter comercial y la Av. Majluta baja en desnivel antes de la intersección, con el fin de crear macromanzanas. Se diseña una vía peatonal que relaciona en sentido norte-sur estas nuevas manzanas y perpendicular a ella se diseñan plazas de carácter diverso: Plaza Hnas. Mirabal con un sentido cívico; Plaza del Comercio, a las actividades comerciales informales; y, Plaza de la Cultura, de equipamientos relacionados con biblioteca, museo y servicios afines, como galerías de arte, que aprovechan el espacio público y el parque que enfrentan. 


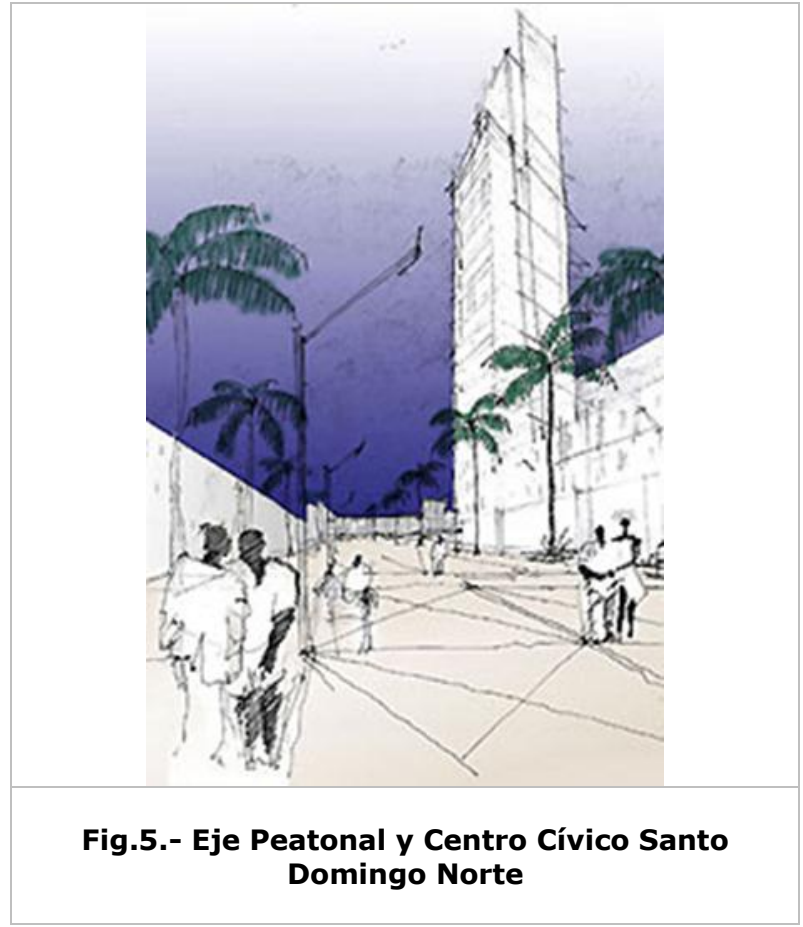

Se propone un parque en sentido oriente-poniente (3 hectáreas), que baja hasta alcanzar el nivel de Av. Majluta. Contempla zona de juegos de niños, áreas para la detención y la contemplación, zona de exposiciones al aire libre, el agua aparece y empieza a constituirse en elemento singular del recorrido, y pequeñas plazas interiores. Los minusválidos tienen la posibilidad de circular y recorrer el parque, los desniveles son diseñados para permitir su desplazamiento, los comercios pueden colocar sus mesas en el exterior para que los peatones disfruten de un café o un refresco. El desnivel generado permite integrar el Centro de Intercambio Modal ubicado bajo la Plaza Hnas. Mirabal y Plaza del Comercio- a éste último en ese nivel con el centro comercial y los cines del área.

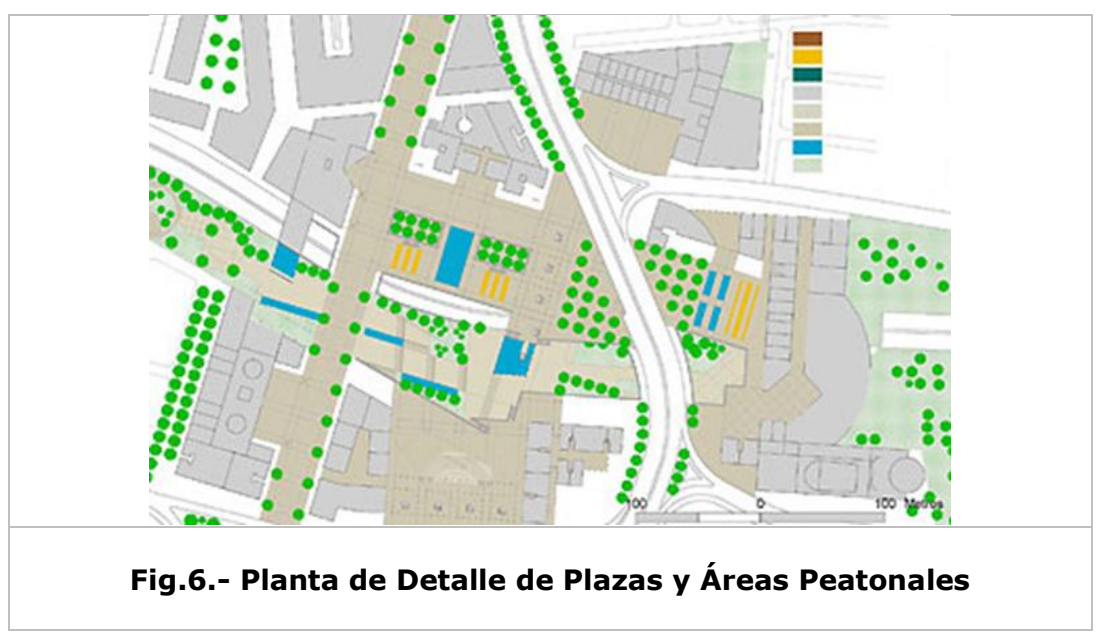


Las macroparcelas con usos diversos y los espacios urbanos se diseñan a fin de ser utilizados durante las 24 horas del día. El programa alberga los servicios comunales, con 4,8 hectáreas (Ayuntamiento, Justicia, Administración Pública, Seguridad y Protección Civil); comercio, servicios privados y equipamiento, con 8,4 hectáreas (tiendas por departamentos, cultura y recreación, salud, educación, pisos de oficinas para profesionales); residencia y servicios privados, con 9,2 hectáreas; y finalmente, en la zona de borde se localiza vivienda. Las edificaciones se proyectan con un primer piso de $5 \mathrm{~m}$ de altura en torno a toda la Plaza Hnas. Mirabal, algunos edificios se liberan en ese nivel con el fin de unir visualmente a ésta con la Plaza del Comercio y la de la Cultura. Se propone en cada zona edificaciones hitos, donde la correspondiente al Ayuntamiento tendría una altura de 80 metros.

En el subsuelo se ubica el Centro de Intercambio Modal de Transporte (Figura No 7), con 6,5 hectáreas. A éste se accede al nivel de la Av. Majluta. Desde él se puede ingresar al Centro Comercial y se posibilita una relación visual con el Parque que se ubica paralelo a esta avenida. Adicionalmente a los andenes (33) propios para la localización de buses y taxibuses, se proyecta una zona especial para taxis (30), y se permite el aparcamiento de 1.000 automóviles particulares. Se ha diseñado un segundo nivel subterráneo (6 hectáreas) para aparcamiento de 2.500 automóviles.

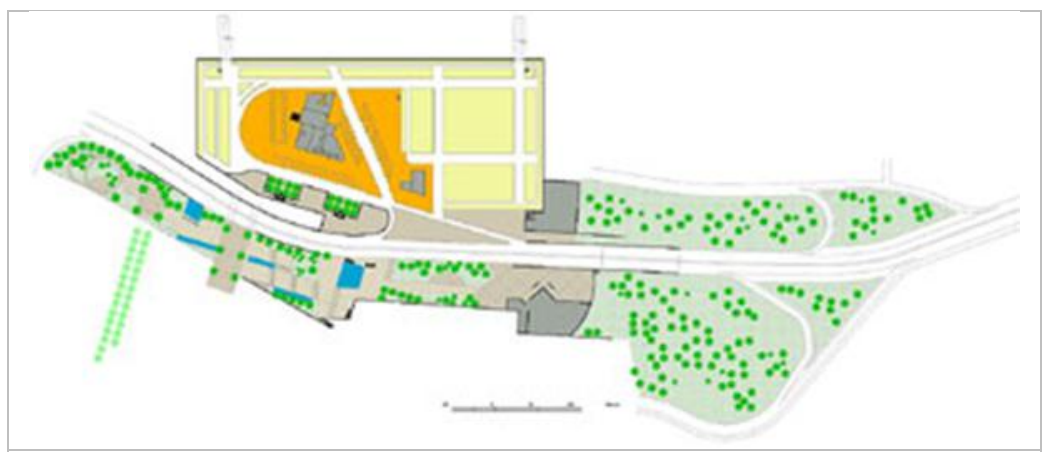

Fig.7.- Planta de Primer Nivel de Subsuelo - Centro de Intercambio Modal de Transporte

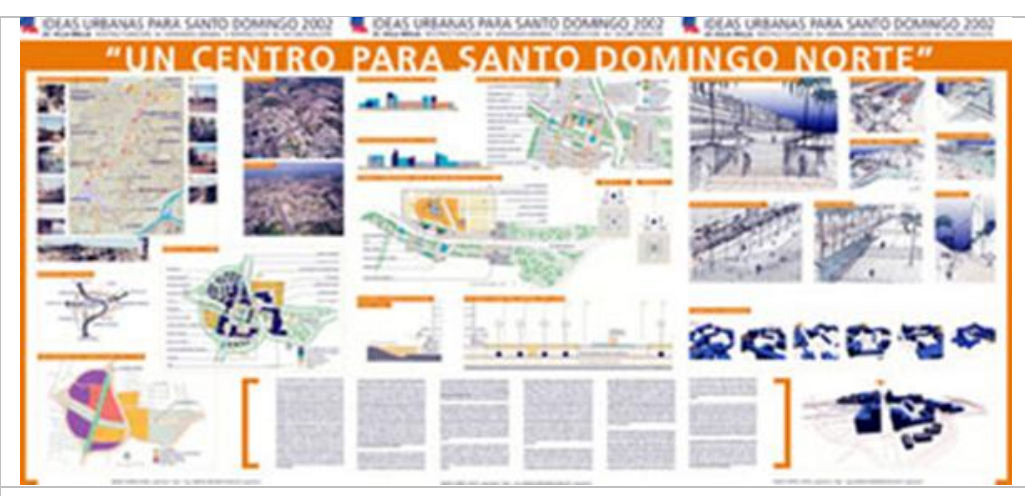

Fig.8.- Paneles Síntesis de Presentación de la Propuesta 
La propuesta tiene un horizonte de materialización en el largo plazo, dado las inversiones que deben desarrollarse. Sin embargo, para que ésta pueda concretarse es necesaria la participación conjunta del sector público y sector privado. Se esperaba que las imágenes directrices y los objetivos establecidos, permitan al Gobierno Local asumir el liderazgo, para dar respuesta a los deseos íntimos de sus ciudadanos. Las ideas de proyecto con las características indicadas permite capturar plusvalías en el valor de la renta del suelo, las cuales correctamente canalizadas pueden y deben transformarse en los flujos financieros del proyecto.

\section{Anillo interior de Santiago}

Con miras a la celebración del Bicentenario, se ha generado un proceso para lograr al 2010 grandes transformaciones urbanas, que se constituyan en herencia a las generaciones venideras. Canaliza y lidera este proceso el DEOB, integrado por el Ministerio de Vivienda y Urbanismo, Ministerio de Obras Públicas, Transportes y Telecomunicaciones y el Ministerio de Bienes Nacionales, con el propósito de proponer y desarrollar acciones, programas y proyectos urbanos (Ministerio de Vivienda y Urbanismo y Bienes Nacionales; 2003, 8 - 9).

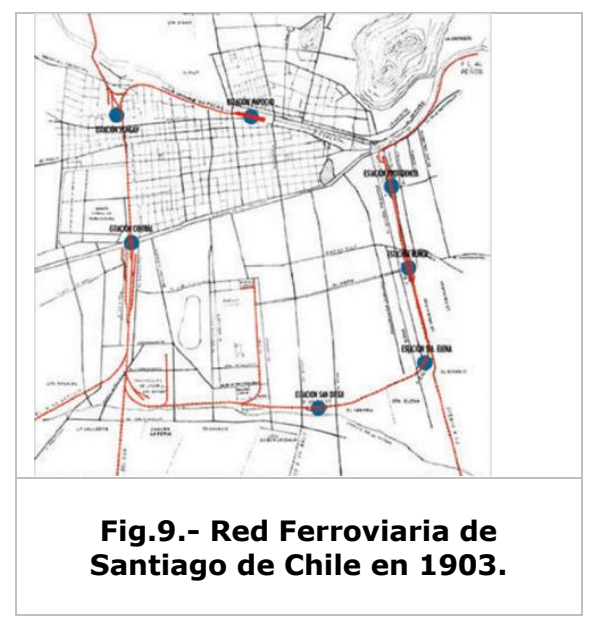

En el contexto de la celebración, el proyecto Anillo Interior de Santiago, pretende la recuperación de las áreas entorno al antiguo cinturón ferroviario -iniciado a fines del siglo XIX- $\mathrm{y}$, que marco durante las primeras décadas del siglo $X X$, el límite de la ciudad de Santiago (Figura No 9). El Plan de Gestión elaborado por el DEOB, con la asesoría de la consultora URBE Diseño y Gestión Urbana, contempló -en una primera fase- invitar a cuatro universidades para elaborar el Plan Maestro; por fines operacionales el área de intervención fue dividida en cinco segmentos, correspondiendo a la Universidad de Chile, a través de la Facultad de Arquitectura y Urbanismo, desarrollar el Plan Maestro para el Segmento D. Los otros segmentos fueron abordados por las universidades: Central de Chile, de Santiago de Chile, Católica de Chile y, por el DEOB. 


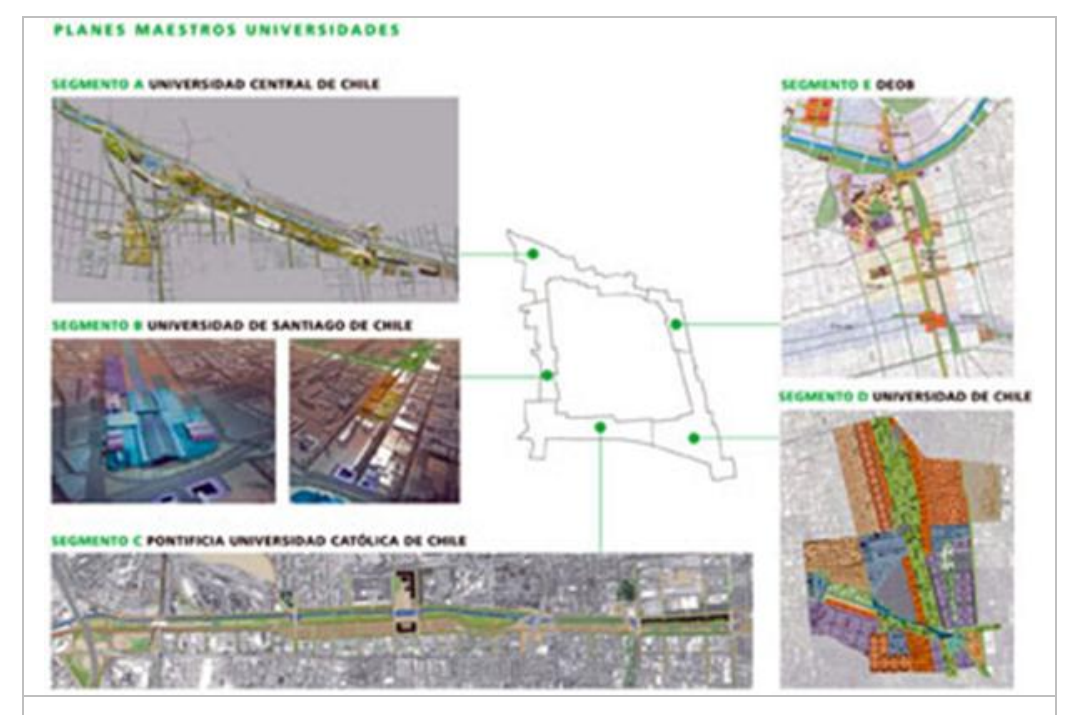

Fig.10.- Planes Maestros de las Universidades y de la DEOB Fuente: Ministerio de Vivienda, Urbanismo y Bienes Nacionales; Directorio Ejecutivo Obras Bicentenario: Anillo Interior de Santiago: Un Desafío de Gestión Urbana Estratégica. Ministerio de Vivienda, Urbanismo y Bienes Nacionales; Santiago; Chile; 2003. p. 56.

\section{Plan Maestro Anillo Interior de Santiago - Segmento D}

Un equipo profesional multidisciplinario desarrolló la propuesta y, adicionalmente a los principios proyectuales del diseño urbano, estableció cinco criterios básicos, a tener presente durante la formulación: a). el diagnóstico elaborado previamente por el DEOB es satisfactorio para la elaboración del Plan Maestro; b). determinar a priori una imagen-objetivo global para el Anillo, basado en el principio de que lo general es más que la suma de las partes; c). el Plan Maestro debe ser la expresión gráfica de los anhelos ciudadanos para el área de intervención en un horizonte de tiempo; d). la propuesta debe oscilar entre el par polar: realidad-utopía; y, e). la celebración del Bicentenario es la coyuntura para el proceso de reflexión sobre una importante área de la ciudad. 


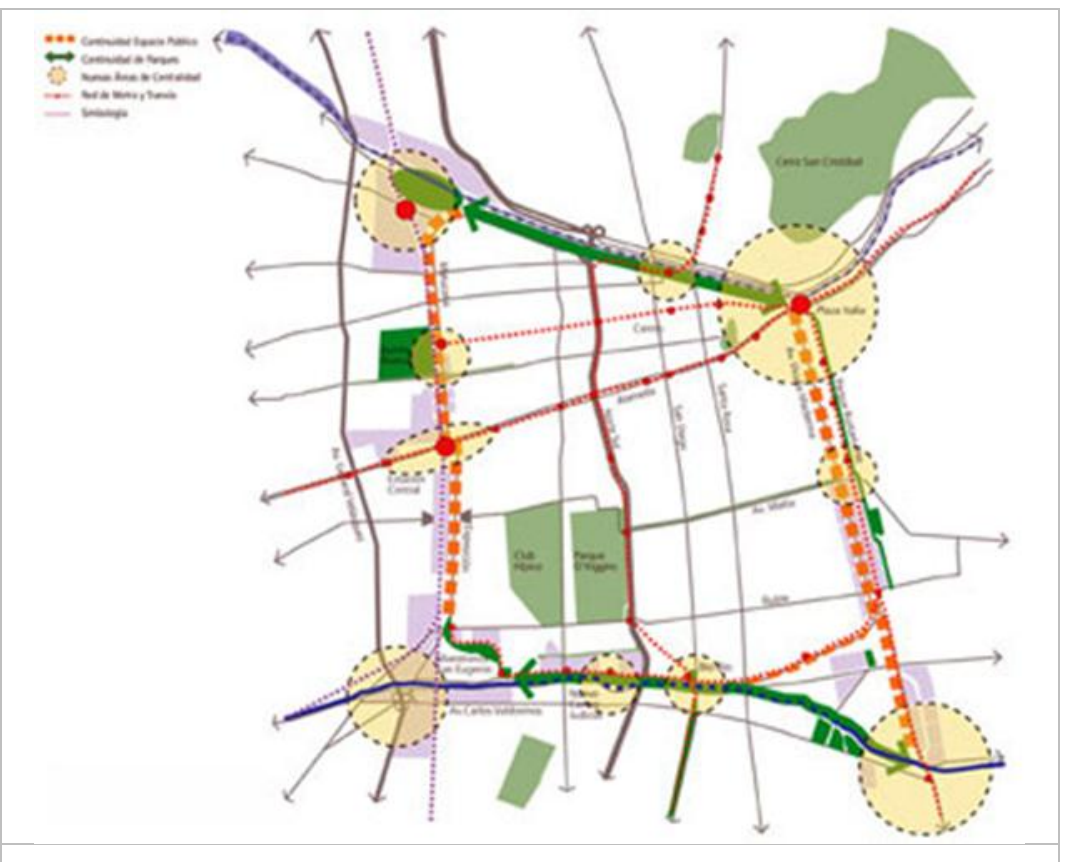

Fig.11.- Estructura Física Base del Anillo Interior de Santiago Fuente: Fuente: Ministerio de Vivienda, Urbanismo y Bienes Nacionales; Directorio Ejecutivo Obras Bicentenario: Anillo Interior de Santiago: Un Desafío de Gestión Urbana Estratégica. Ministerio de Vivienda, Urbanismo y Bienes Nacionales; Santiago; Chile; 2003. p. 41.

Concebimos a la ciudad no como un mero programa de funciones o actividades entrelazadas, sino que ante todo morada por excelencia del hombre. De aquí es que en la imagen-objetivo para el Anillo se privilegie el «ser» sobre el «tener», se formula entonces la idea fuerza: «Santiago Capital Integral» y para el Segmento D: «un nuevo enlace»; se trata de un salto cualitativo, pasar del «Zanjón de la Aguada al Parque del Enlace».

Para posibilitar el desarrollo integral del hombre, el Plan, cumple con cuatro roles: de Sistema de Vialidad y Transporte; de Sistemas de Espacios Públicos y Áreas Verdes; de Sistema de Parques o Subcentros Temáticos; y, de Comunidades Vivas. Éstos dan coherencia a la imagen-objetivo propuesta, dado que los problemas y desafíos de la zona no son simples ni de fácil solución: baja densidad poblacional, homogeneidad socioeconómica, estigma, abandono, deterioro, pobreza, obsolescencia de las estructuras, falta de equipamiento de escala comunal y barrial, usos molestos y ofensivos, contaminación visual y olfativa, inundaciones, baja valoración de las edificaciones y zonas patrimoniales, falta de jerarquización de la estructura vial, déficit de áreas peatonales, superávit de espacios para vehículos de tracción mecánica, entre otros. 


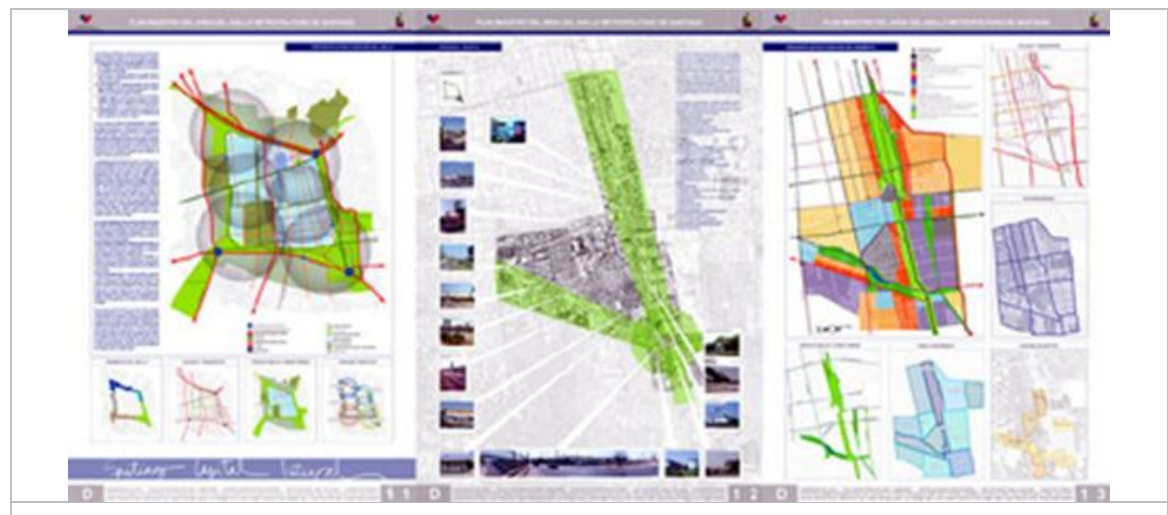

Fig.12.- Conceptualización, Problemas y Estructuración del Segmento D

Considerando la dimensión morfológica del diseño urbano, se establece una estructuración basada en cinco aspectos: Vialidad y Transporte, con corredores de transporte público, optimización de la red de Metro, incorporación de tranvía o tren ligero, estaciones de transferencia modal, corredores de transporte privado, ciclovías, vialidad local; Macromanzanas, servidas en sus bordes por corredores de transporte público, autosuficientes y sustentables, con usos preferentes y no exclusivos, con ocupación interior de la manzana; Espacios Públicos y Áreas Verdes, recuperación del espacio público para el peatón, construcción de bulevar, construcción de parques, habilitación de vías parques; Usos del Suelo, residencia en alta y media densidad (colectiva y unifamiliar), comercio y servicios, equipamiento de educación, salud, cultura, esparcimiento y recreación, áreas cívicas, industria y tecnología, zonas de conservación patrimonial; y, Áreas Homogéneas y Unidades de Gestión, en función de las características morfológicas, legales y normativas, de resistencia al cambio, de tenencia del suelo.

El Plan Maestro del Segmento D se orienta a la producción de suelo recualificado en una zona de 723 hectáreas. En función de los usos preferentes de cada zona, se destinan 86 hectáreas para residencia en alta densidad; 130 hectáreas, de residencia colectiva en media densidad; 116 hectáreas, de residencia unifamiliar en media densidad; 62 hectáreas, de comercio y servicios; 148 hectáreas, para la industria y la tecnología; 120 hectáreas, de parques públicos; 7 hectáreas, para bulevar; y, 62 hectáreas, de zonas de conservación. Para el logro de los objetivos se proponen acciones de corto, mediano y largo plazo, en escenarios de desarrollo asociados a proyectos estratégicos. Las imágenes específicas para los proyectos estratégicos utopías urbanas de cara a nuestra realidad-, son producto de la relación entre los objetivos a alcanzar y las propuestas normativas para intervenir en cada zona. 


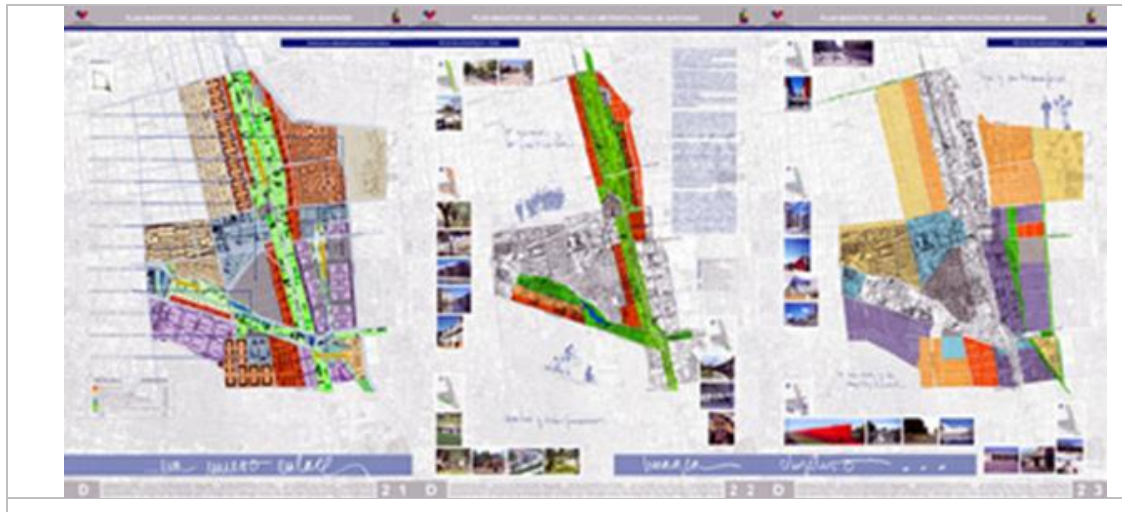

Fig.13.- Propuesta Urbano Arquitectónica e Imagen-Objetivo

Eliminar el estigma negativo de la zona es la primera prioridad del Plan, el «Parque del Enlace» es la propuesta, factible de materializarse con el saneamiento del Zanjón de la Aguada. Las acciones a desarrollar posibilitan eliminar las inundaciones producto de las precipitaciones; se diseña una laguna de laminación, capaz de retener las aguas lluvias y encauzarla hacia nuevos canales de conducción, los cuales forman parte de senderos de agua dentro del parque. Áreas de equipamiento deportivo y recreativo, tanto para los habitantes como para las nuevas unidades de comercio, servicio y equipamiento, complementan las actividades de los bordes. Los perfiles de las vías, se rediseñan y se incorpora la faja para el ramal del tranvía o tren ligero hacia el oriente de la ciudad.

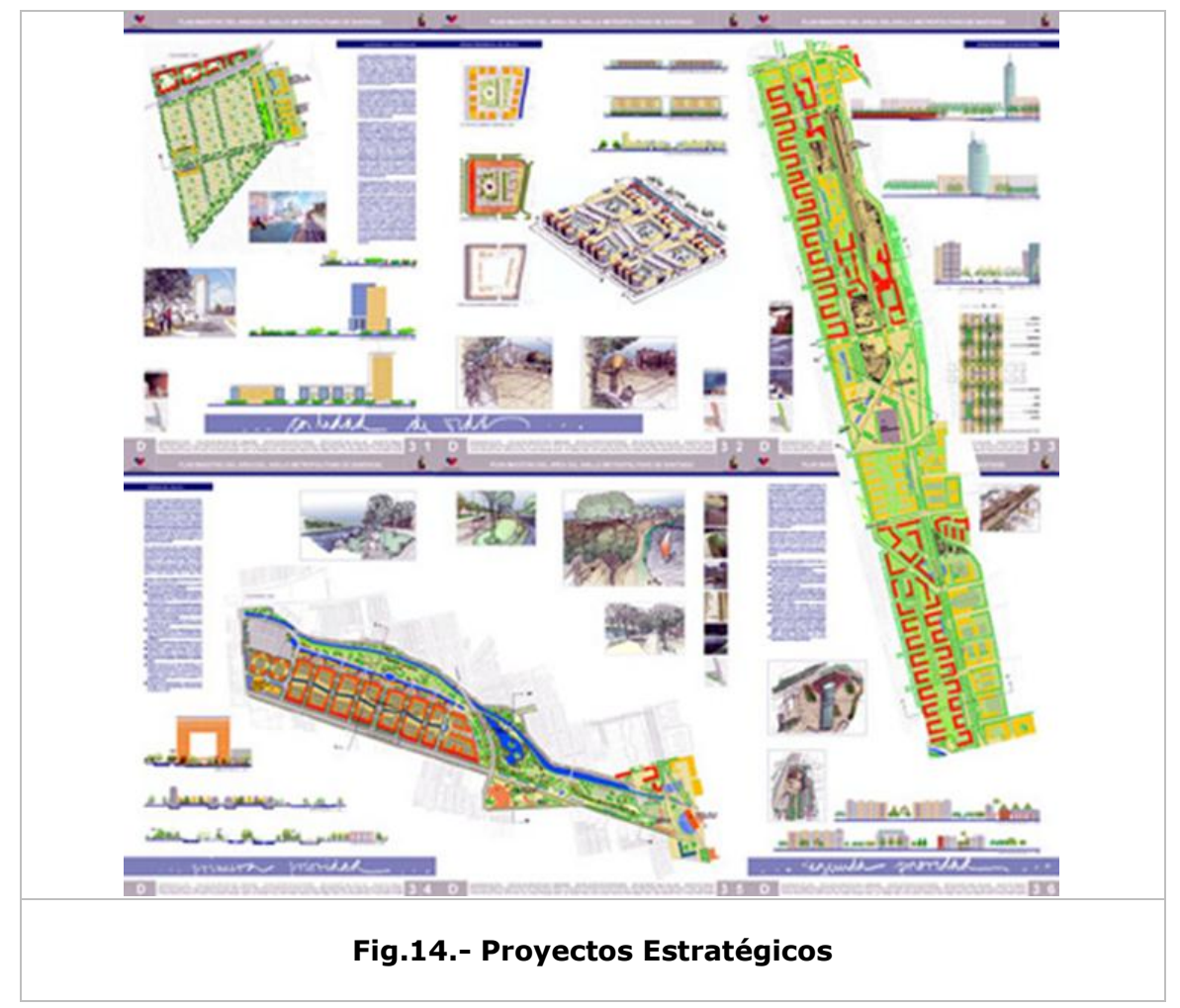


El «Parque Bulevar Vicuña Mackenna», es la segunda prioridad del Plan; postula la exclusividad de la Av. Vicuña Mackenna como corredor de transporte público, con una adecuada reconversión del espacio público. La Plaza de La Viña, asociada a la recuperación del espacio público de Viña Manquehue, posibilita la localización de la estación de transferencia tranvía-metro. La norma propende a la densificación de los bordes de la Av. Vicuña Mackenna, con franquicias adicionales en la liberación de suelo en las primeras plantas, todo ello asociado al nuevo diseño del espacio público, incorporándose la ciclovía en toda su longitud.

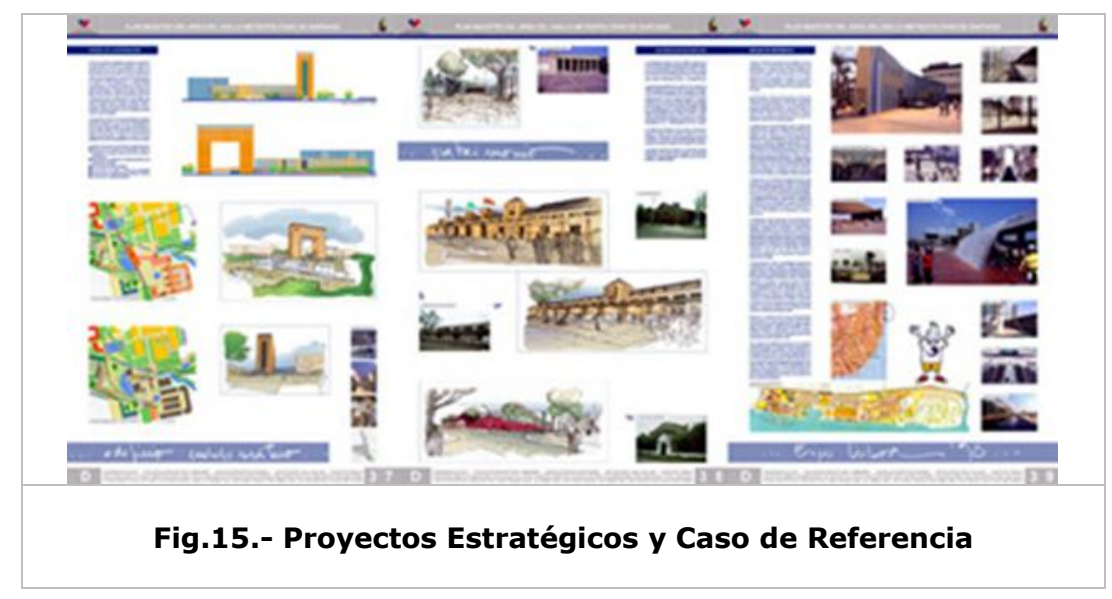

Para acoger nuevos habitantes, se proponen dos proyectos de residencias; además contribuyen a mejorar la calidad de vida de los barrios. Zonas de 26 hectáreas de suelo cada una, que se conciben conjugando diversos tipos de soluciones habitacionales, para lograr heterogeneidad espacial y, especialmente, sociocultural y económica; además, los equipamientos que permiten satisfacer las necesidades de la población residente. El «Parque Residencial del Enlace», localizado dentro del Parque del mismo nombre, alberga 2.300 viviendas con una densidad de 350 hab/ha; las edificaciones presentan alturas entre las 4 y las 10 plantas. El «Parque Residencial Bulevar Vicuña Mackenna», localizado al norte de la principal área de conservación residencial, se proyecta para 1.400 viviendas con una densidad de 240 hab/ha; la propuesta tipológica presenta mayoritariamente viviendas unifamiliares en dos y tres plantas, con excepción del borde norte -asociado a la faja vía para el tranvía- y el borde oriente, que se destina a equipamiento de escala intercomunal.

Asociado a los proyectos prioritarios, está el «Portal de la Integración», que posibilita hacer realidad la unión entre el sur de la ciudad y la zona central, creando una puerta en el nudo vial formado por las avenidas Vicuña Mackenna, Quilín, Carlos Valdovinos e Isabel Riquelme. Contempla la localización del centro de intercambio modal de transporte (en la Estación Carlos Valdovinos); un edificio destinado a equipamiento de escala metropolitana (comercio, servicios, oficinas, hotel y esparcimiento) en el predio de hormigones Grau; un edificio portal sobre la estación del Metro; edificios para estacionamientos de automóviles. Además, la Plaza de la Integración y el Parque de la Tecnología. 
El Plan Maestro, postula la recuperación y puesta en valor de edificios singulares y conjuntos urbanos: Manufacturas Sumar, Viña Santa Carolina, Ex Estación San Eugenio, Viña Manquehue, Silos Lucchetti, Barrio Grandes Compositores. Adicionalmente a la recuperación y mantención de las edificaciones, se diseña y recupera el espacio público que enfrentan.

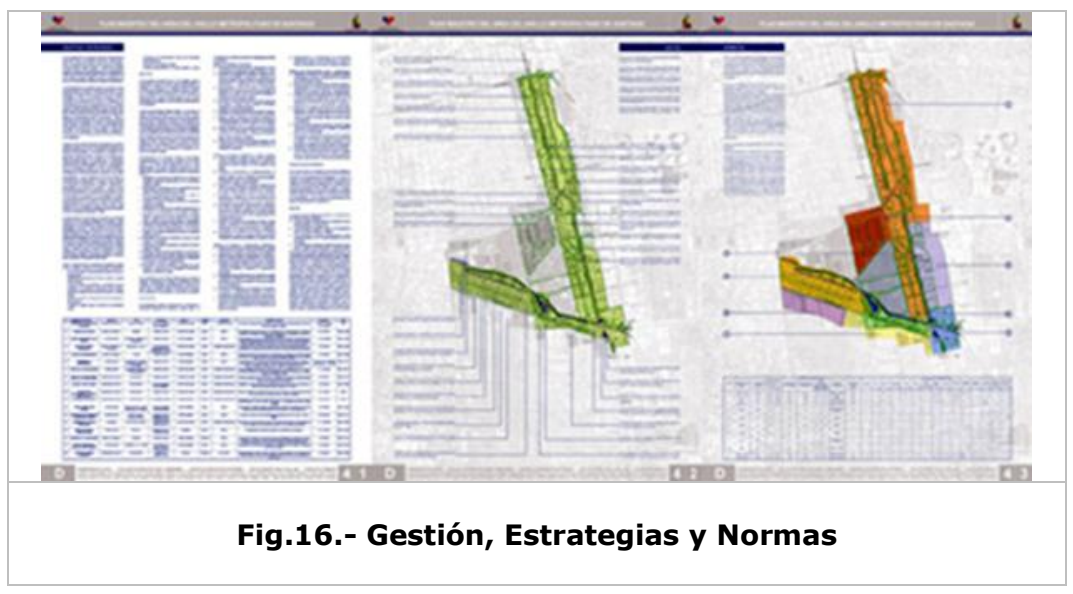

Con una propuesta de gestión concluye el Plan. En ella, se establecen 14 objetivos generales; cuatro conjuntos de estrategias; 18 proyectos priorizados, para materializarse en un horizonte mínimo de 10 años; un plan seccional, que define nueve zonas, para la ejecución de las acciones; una síntesis de actores relevantes; y, las fuentes de financiamiento.

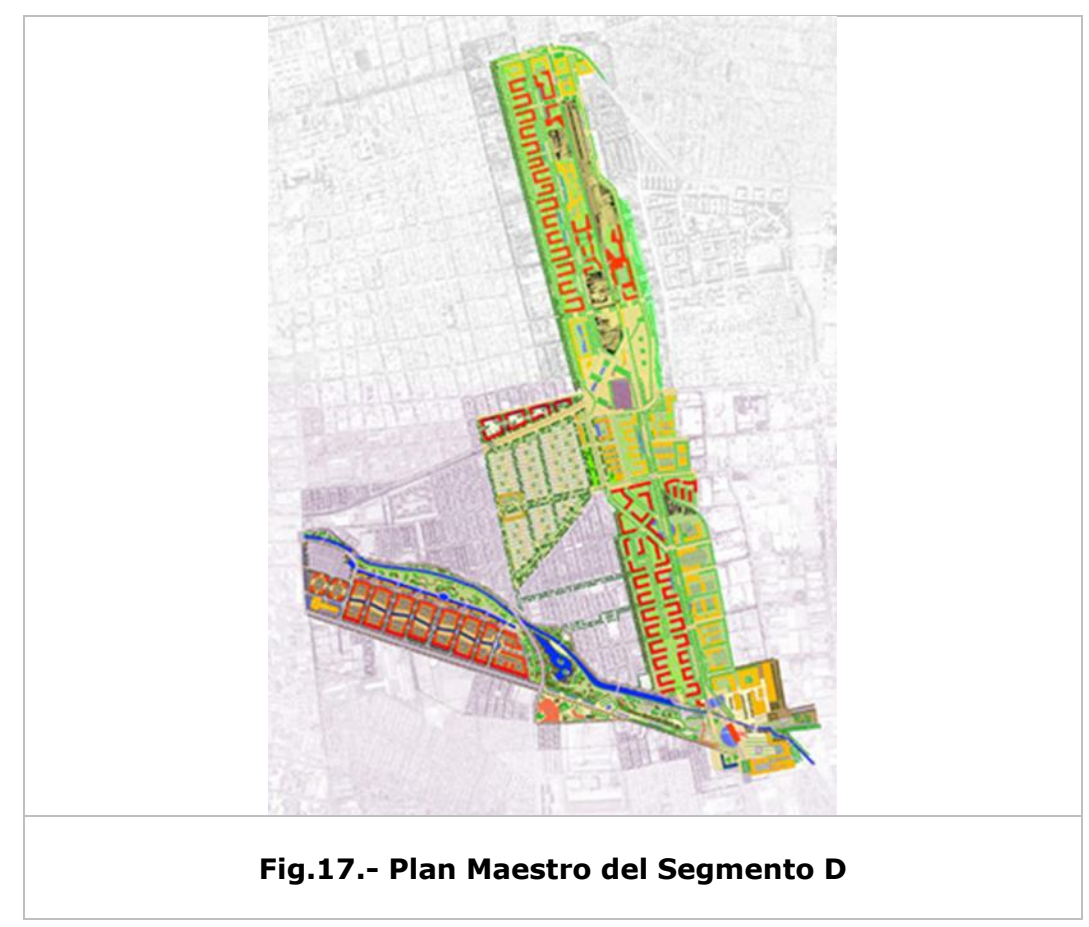




\section{Plan Maestro y Seccional Maestranza San Eugenio}

Un predio importante en el Plan Maestro del Segmento C (que fuera desarrollado por la Universidad Católica de Chile), no sólo por la superficie que posee, sino en forma muy especial por su localización, es el que corresponde a la Maestranza de San Eugenio. Para esta propiedad el DEOB licitó el estudio: «Análisis Patrimonial, de Gestión e Inmobiliario Maestranza de San Eugenio» y fue adjudicado a la Facultad de Arquitectura y Urbanismo de la Universidad de Chile. Entre los productos solicitados estaba el Plan Maestro y Seccional correspondiente, respecto de los cuales nos referimos a continuación.

El proyecto comprende el predio de la Maestranza de San Eugenio, de propiedad de la Empresa de Ferrocarriles del Estado (EFE), de Inmobiliaria Nueva Vía S. A. (INVIA S. A.) y de Técnicas Modulares e Industriales S. A. (TEMOINSA), que constituye un paño de aproximadamente 43 hectáreas y que se emplaza en la comuna de Estación Central.

La Maestranza de San Eugenio es el vértice surponiente del Anillo Metropolitano y se sitúa estratégicamente en relación con el cuadrante para esa zona y que integra a las comunas de: San Miguel, La Cisterna, El Bosque, Pedro Aguirre Cerda, Lo Espejo, Estación Central, Cerrillos, Maipú y San Bernardo. En la Figura No 18 se puede apreciar la localización del predio (en color rojo) respecto de la zona central de la ciudad y su relación con el cuadrante surponiente (en color amarillo, aparece el proyecto del Portal Bicentenario, localizado en el Aeropuerto de Los Cerrillos).

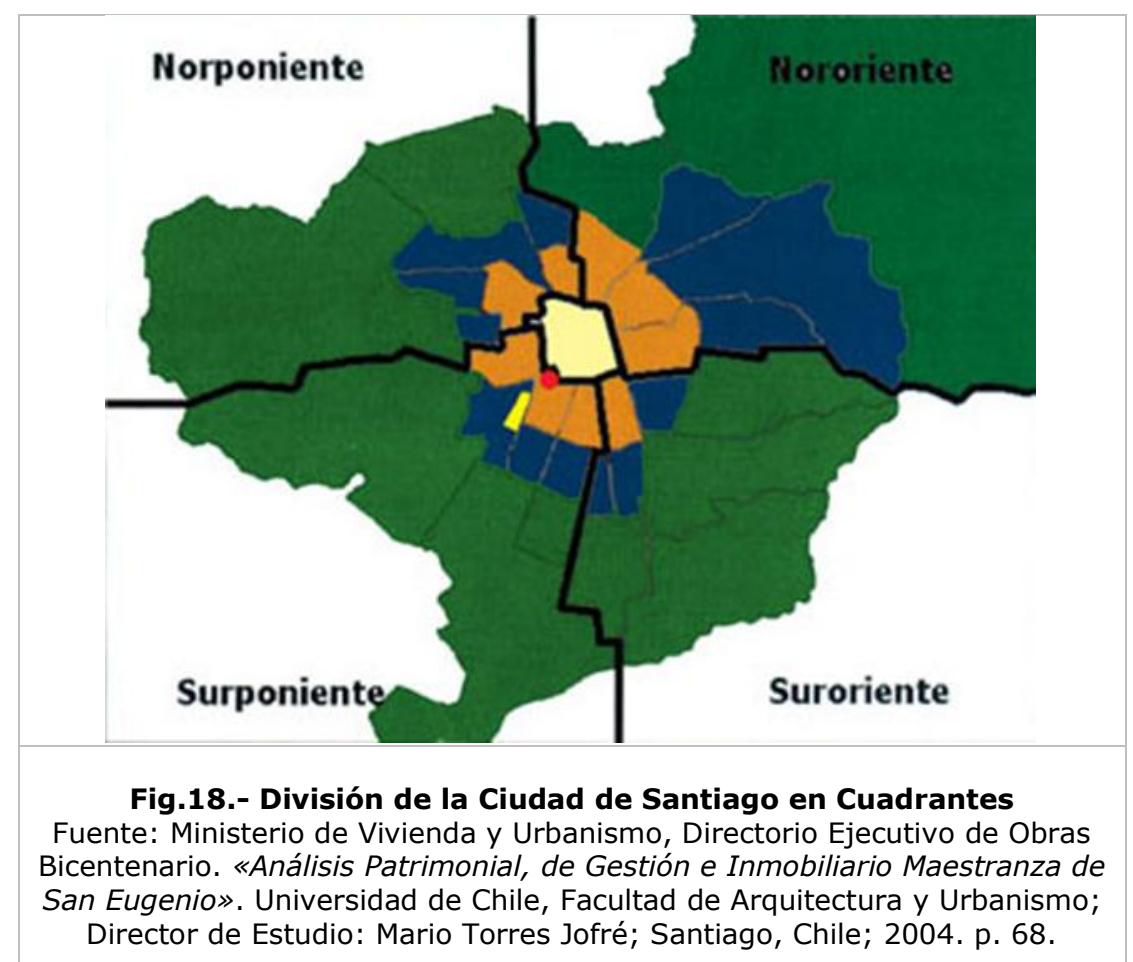




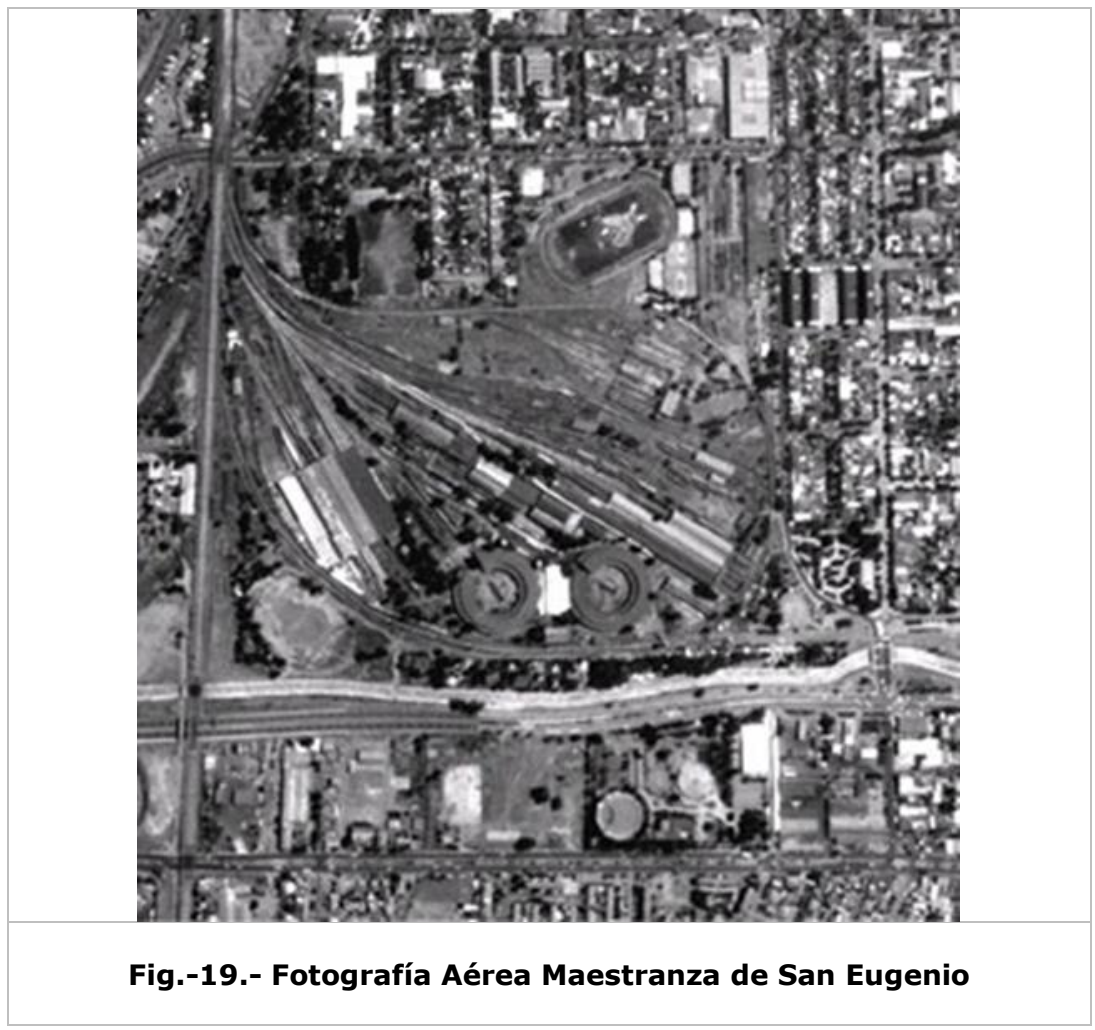

El predio de la Maestranza de San Eugenio, con relación al proyecto Anillo Interior de Santiago, es considerado como nodo para dar continuidad al espacio público constituido por el proyecto del parque adyacente al cauce del Zanjón de la Aguada (Parque de la Aguada o Parque del Enlace) y su prolongación hacia el norte, por calle Exposición hasta su conexión con el Bulevar Matucana. Además, articulador e integrador del sector surponiente de la ciudad como nueva área de centralidad, capaz de generar un proceso de renovación urbana.

La localización de la Maestranza de San Eugenio en esta zona de la ciudad data del año 1894, según la inscripción de los títulos de propiedad, en el Conservador de Bienes Raíces de Santiago, es decir -al menos- tiene 110 años. A más de cien años de la entrada en funcionamiento del Ramal Ferroviario de Circunvalación de Santiago (ver Figura No 9), la historia y los proyectos vuelven a unirse para definir la estructura de la zona central de la ciudad. Desde el punto de vista del desarrollo inmobiliario, ésta se encuentra asociada a la evolución industrial $y$, a partir de ella, la aparición de la vivienda y el equipamiento para los hogares existentes en la zona.

En las 43 hectáreas que posee el predio referido a la Maestranza de San Eugenio y en las propiedades privadas existentes dentro de la zona de análisis se puede apreciar una gran diversidad de edificios. La densidad, en función de la altura de edificación, es bastante baja, sin embargo, en las zonas de vivienda la densidad es alta, dado el tamaño predial y las edificaciones de vivienda colectiva existente. Predomina la 
heterogeneidad de usos del suelo, sin embargo, en cuanto a superficie ocupada, la zona es predominantemente industrial.

El estudió postuló tres escenarios de configuración espacial y funcional para dar origen al Plan Maestro, de la evaluación de las ventajas y desventajas de cada uno de ellos se elaboró la propuesta final, denominada Maestranza 21. Si bien los tres escenarios preliminares ofrecían configuraciones diversas, ellos se fundamentaban en idénticos criterios respecto del Proyecto Anillo Interior de Santiago, al patrimonio urbanoarquitectónico, al plan de transporte público y a las condiciones económicas exigidas a la venta del suelo por el propietario, en este caso, INVIA (empresa inmobiliaria de Ferrocarriles del Estado).

Las características espaciales del recinto, su ordenamiento en función de uso original, el patrimonio urbano-arquitectónico que revisten algunas de las edificaciones son aspectos que los escenarios de configuración y la propuesta final acentúan. Los edificios tornamesa y las bodegas adyacentes son puestos en valor, al igual que la característica estructural que posee la «pera» de la parrilla ferroviaria, elementos que se encuentran presentes en la memoria colectiva, asociada al área ferroviaria de la ciudad de Santiago.

Se reconoce la importancia que reviste el Plan de Transporte Urbano para la ciudad de Santiago (Transantiago), en especial, para el centro de la ciudad. Así, se propende a desincentivar el uso del automóvil dotando de espacios que privilegien el recorrido peatonal y el uso de la bicicleta. La configuración espacial distingue en la faja vía de ferrocarriles el potencial, para la puesta en marcha de un tranvía o bus de alto estándar que permita circunvalar el centro de la ciudad.

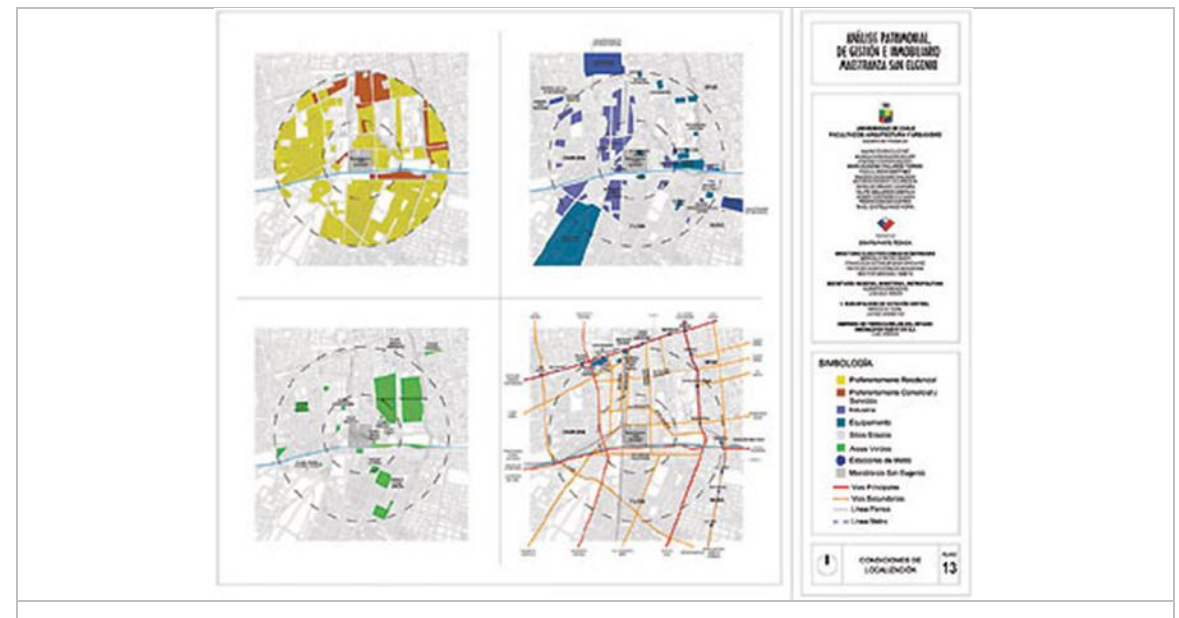

Fig.20.- Condiciones de Localización de la Maestranza de San Eugenio Fuente: Ministerio de Vivienda y Urbanismo, Directorio Ejecutivo de Obras Bicentenario. «Análisis Patrimonial, de Gestión e Inmobiliario Maestranza de San Eugenio». Universidad de Chile, Facultad de Arquitectura y Urbanismo; Director de Estudio: Mario Torres Jofré; Santiago, Chile; 2004. p. 67. 
Una constante en los escenarios, fue la conservación -en cuanto a superficie y a uso se refiere- del Área Verde Complementaria (equipamiento recreacional y deportivo) Estadio San Eugenio, localizado al interior de la Maestranza con una superficie cercana a las 4 hectáreas. Sin embargo, se flexibiliza -en virtud de la configuración espacial y funcional- su localización al interior del predio.

La propuesta de Plan Maestro y Seccional Maestranza San Eugenio hace suya los objetivos de la Agenda 21, apostándose por el fomento de la economía urbana sostenible, la ordenación del territorio integrada a la planificación del transporte y la planificación espacial, para mejorar la ciudad. Del mismo modo, recoge los postulados de la Conferencia de Estambul, que pone relevancia en la necesidad de protección de áreas periféricas de las ciudades y de las zonas verdes urbanas, la necesidad de la utilización de fuentes de energía renovables y nuevos diseños en las políticas sobre sistemas de comunicación y transporte más eficientes.

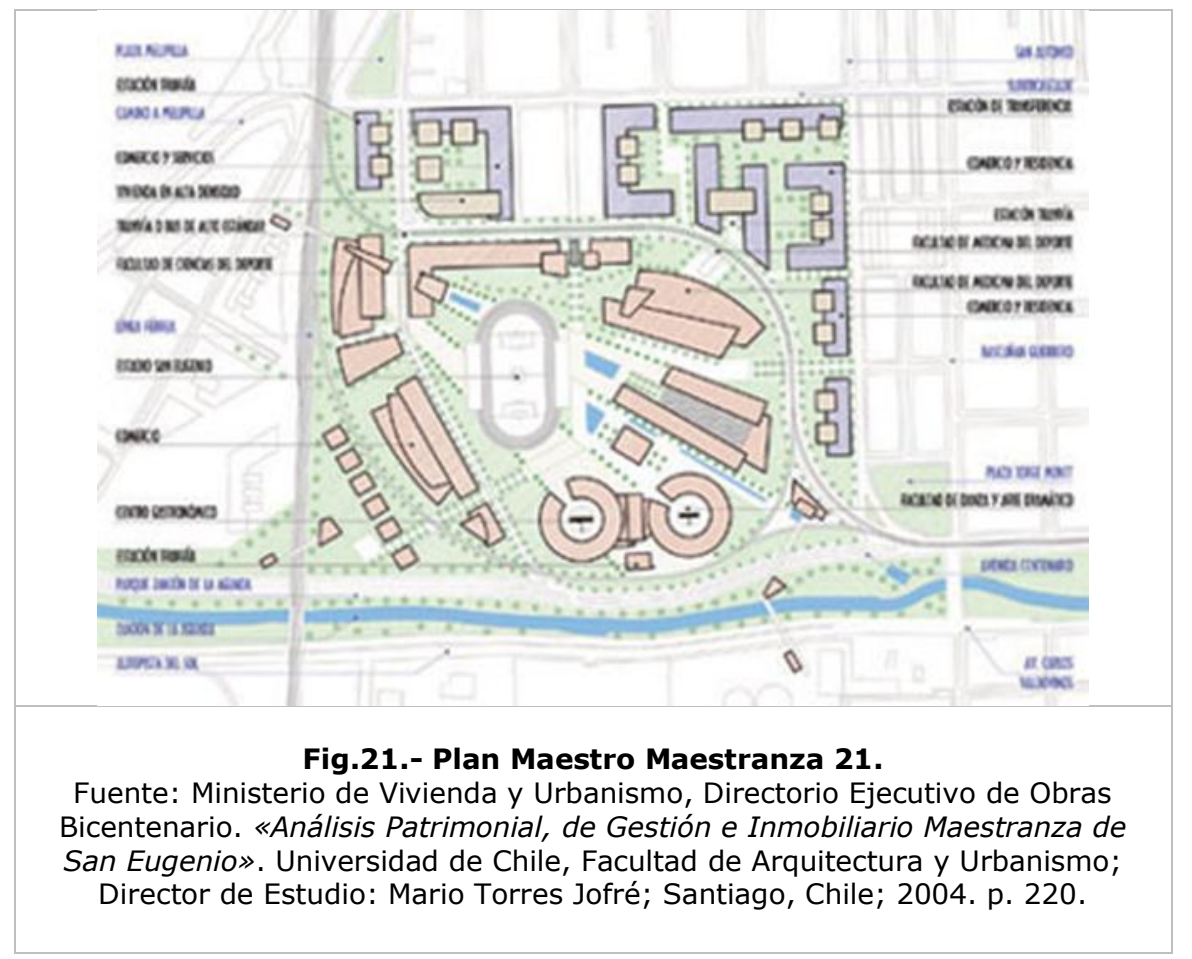

Los criterios y objetivos utilizados reconocen la complejidad y dinámica del desarrollo urbano de la ciudad y acentúan la mirada de largo plazo, reorientando la forma de crear ciudad y de lograr calidad de vida. Además, la reconversión del predio de la Maestranza de San Eugenio se potencia como foco de desarrollo urbano del centro de Santiago.

Maestranza 21, posibilita incorporar 43 ha al desarrollo urbano de la zona central de la ciudad, incentivando la reconversión de aproximadamente 200 hectáreas deterioradas en el Área de Impacto, las cuales se localizan -fundamentalmente- al sur y poniente del predio. Con relación al poniente de la línea férrea, se espera que el desarrollo 
económico y la dinámica de renovación de esta zona -en el largo plazo- posibiliten construir en forma subterránea la red ferroviaria del tren al sur, desde algunos kilómetros antes al cruce con la Autopista de Sol y se pueda acceder directamente a la Estación de Intercambio Modal de la Quinta Normal, para lograr la recuperación de todos los suelos a nivel de superficie que corresponden a la faja vía y a la Estación Central.

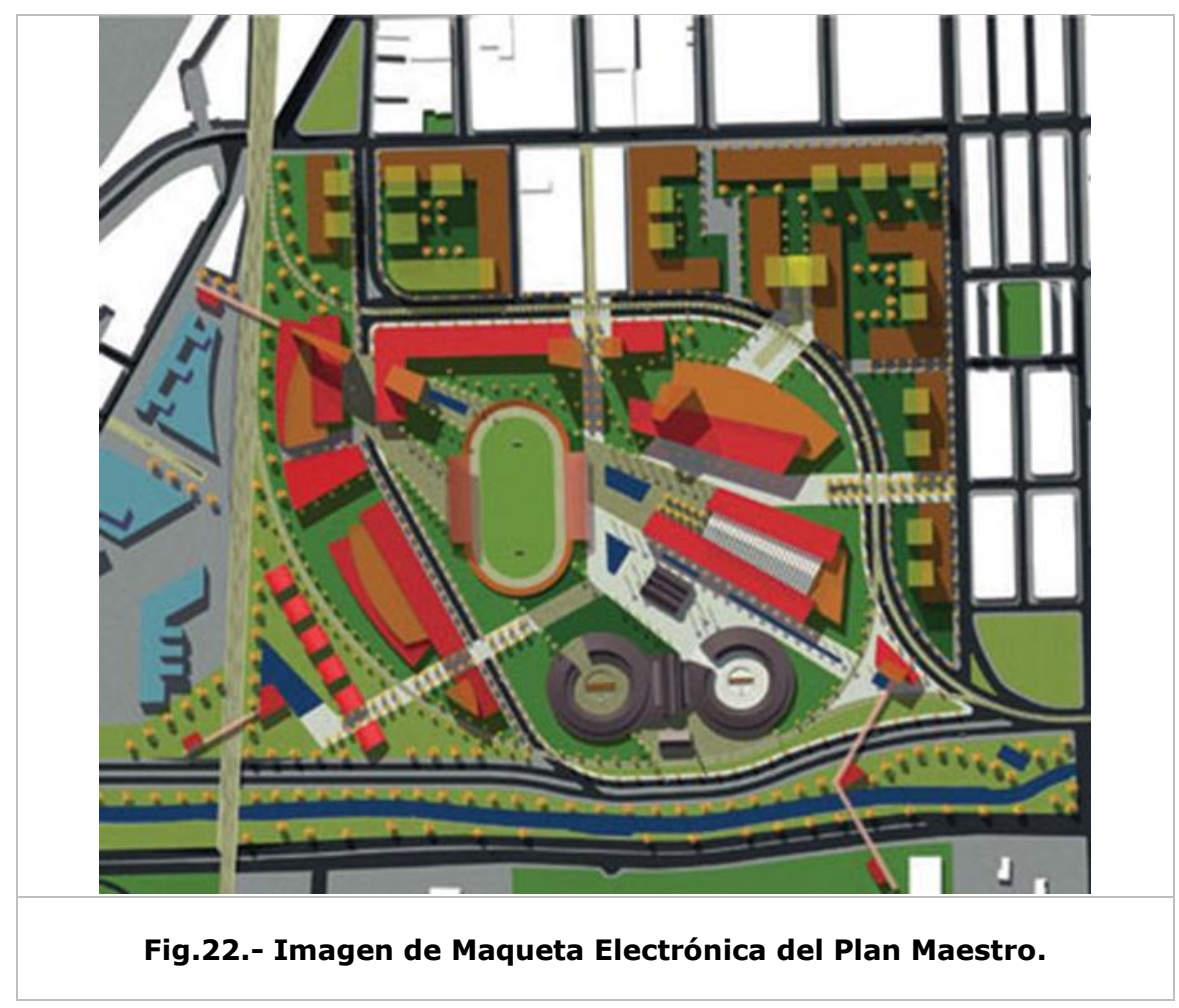

Maestranza 21 destina 25 hectáreas netas para el desarrollo inmobiliario con aproximadamente 900 mil metros cuadrados de superficie edificada. De éstos, un $28 \%$ son para la localización de vivienda. Se reservan 8 ha para el Parque del Enlace y de protección patrimonial asociada al resguardo de los edificios -evaluados y jerarquizados- existentes al interior del predio.

Maestranza 21 posibilita la construcción de 3.500 viviendas en el centro de la ciudad, con una excelente conectividad y accesibilidad por medio del transporte público. Se obtiene una alta calidad residencial por centralidad y cercanía a zonas de excelente calidad ambiental y paisajística.

Maestranza 21 incentiva el uso del transporte público, dada su relación directa con el programa Transantiago y el uso del modo a pie y en bicicleta. Desincentiva el uso del automóvil, aunque facilita que sus residentes tengan la posibilidad de poseer un vehículo, exigiendo zonas de estacionamiento en el subsuelo para todos los proyectos inmobiliarios. 


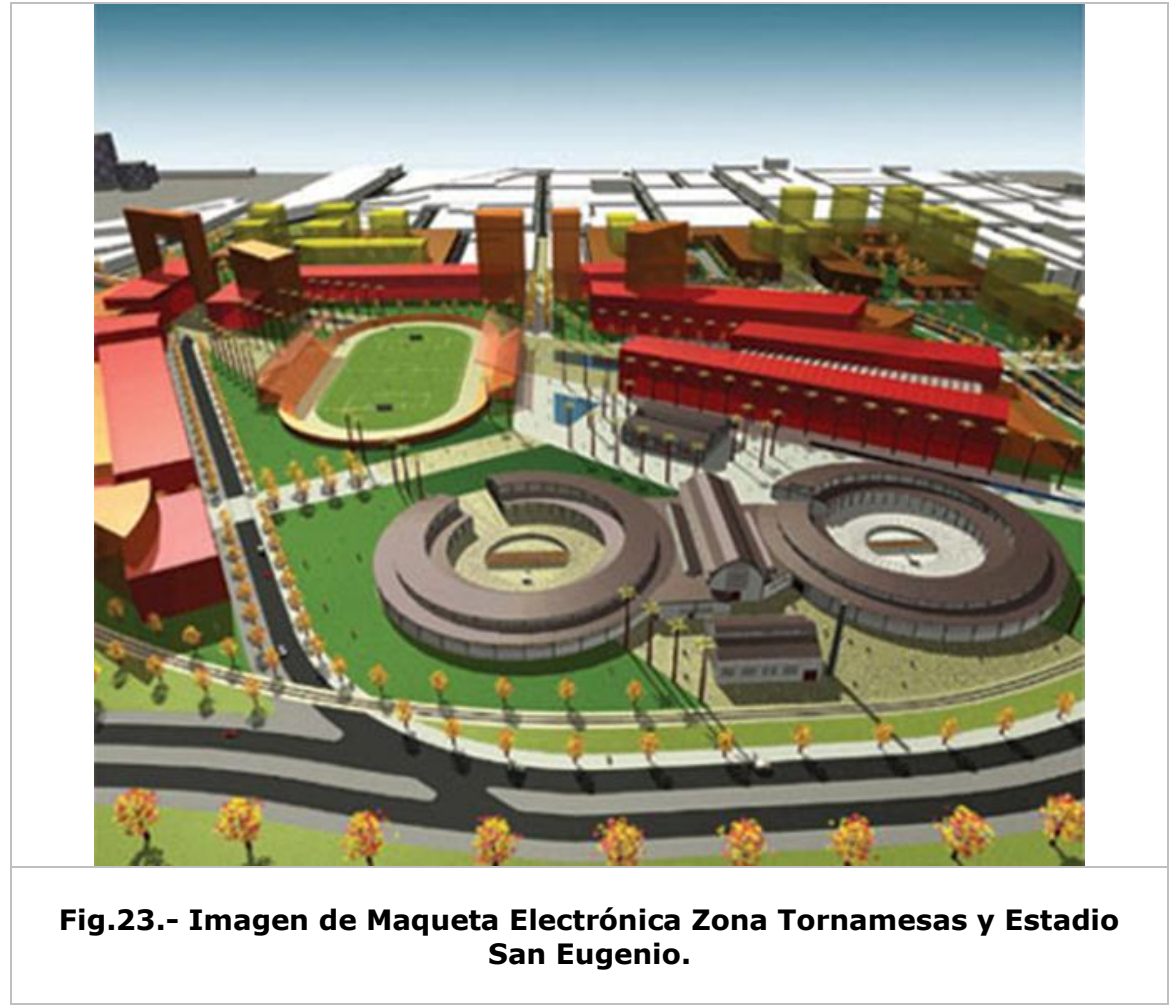

Las normas que se asocian a Maestranza 21 liberan en promedio el $40 \%$ de los suelos para áreas libres de los emprendimientos inmobiliarios, con exigencias de zonas verdes y arborización, de modo que las 43 hectáreas se transformen en otro pulmón verde de la ciudad.

Maestranza 21 se potencia como centralidad metropolitana, con diversidad de usos y actores. En ella tiene cabida la cultura, el deporte y la recreación, de modo de facilitar el uso del tiempo de ocio, que mejora la calidad de vida de los habitantes. La educación y la salud son otro de los aspectos que se incentivan para su desarrollo.

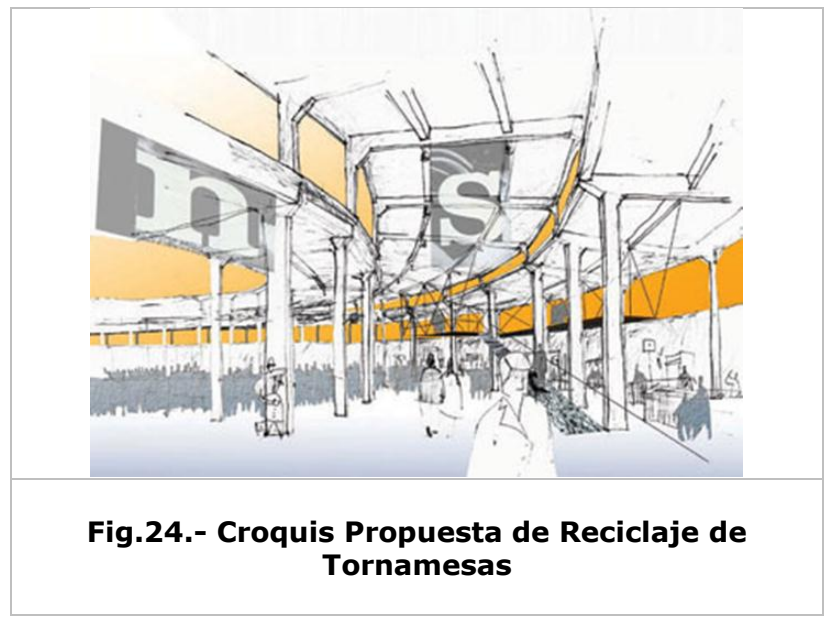


Maestranza 21 propone tres grandes zonas preferentes de usos y actividades. La zona de borde, que se estructura entre las calles Subercaseaux y San Alfonso y la vía interior propuesta -que posibilita la conexión entre calle Exposición y Av. Centenario-, esta zona posee la característica de enlace con los bordes residenciales existentes. La vía propuesta incorpora en el centro de su perfil un espacio para la circulación del tranvía o bus de alto estándar, que viabiliza la conectividad con el norte, sur y oriente de la ciudad. En la zona de borde se privilegia primordialmente la localización de vivienda y comercio, este último, directamente relacionado con la estación de transferencia de transporte público.

Una segunda zona corresponde al área central del predio, la cual se destina principalmente a equipamiento de escala intercomunal $\mathrm{y} / \mathrm{o}$ metropolitana, que reconoce el rol del predio como cabeza del cuadrante sur-poniente de la ciudad. En ella, tiene importancia el sector que se destina a la reubicación del Estadio San Eugenio y la de resguardo patrimonial, con los edificios de interés patrimonial. El desarrollo total de esta zona estará vinculado directamente a la materialización del proyecto de tranvía, que permite el recorrido del Anillo. El Estadio San Eugenio vinculado a un Club de Deportes de nivel internacional o a una Universidad, y la zona de interés histórico, que persigue la conservación y recuperación de los edificios de interés patrimonial, que ocupan una superficie aproximada de 9 hectáreas, integrándose en una sola unidad espacial. En esta zona de equipamiento se propone la localización de un complejo hotelero y de un hospital clínico asociado a un centro de educación universitaria.

La tercera zona es aquella donde se localiza la empresa TEMOINSA, la cual mantiene el uso asociado a infraestructura de transporte, que en mediano a largo plazo podría cambiar a actividades productivas inofensivas y no contaminantes.

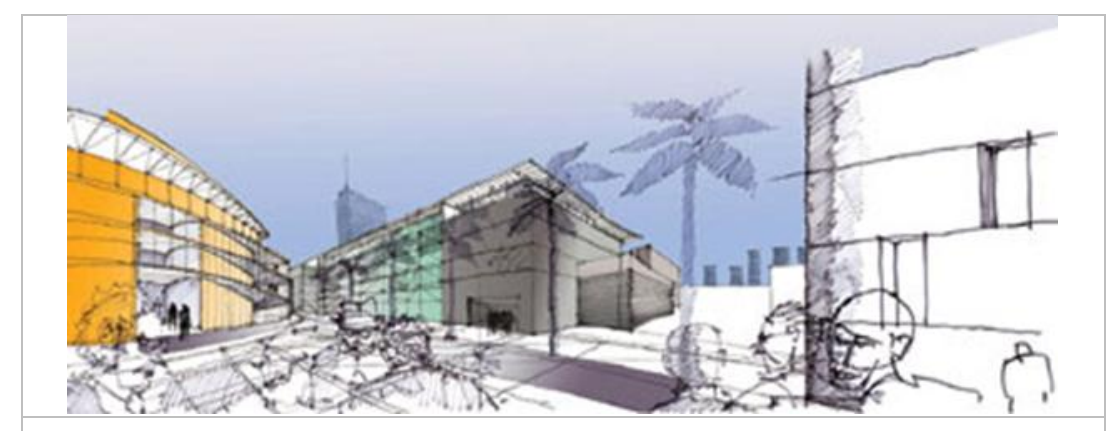

Fig.25.-Croquis Zona de Equipamiento Adyacente a Tornamesas.

Para la gestión del Plan Maestro de reconversión de la Maestranza de San Eugenio, como forma parte del Proyecto Anillo Interior de Santiago, se considera a nivel general, la estrategia de gestión del proyecto generatriz. En este contexto, las estrategias de gestión dicen relación con el territorio, el financiamiento, la administración y de posicionamiento y comunicación. 
El Plan de Gestión propuesto desarrolla ocho temáticas de acciones para materializar el proyecto Maestranza 21. En primer lugar define la Estrategia de la Gestión; luego centra la gestión en la Creación de Asociación de Actores Involucrados; propone los mecanismos para Establecer Consensos; establece la forma de Gestión de la Enajenación del Suelo; mecanismos para la Gestión de la Conservación del Patrimonio; el proceso para encarar laGestión del Desarrollo Inmobiliario; la formulación de la Gestión del Sello de Marca; y finalmente, la necesaria e inevitable Gestión del Corto Plazo.

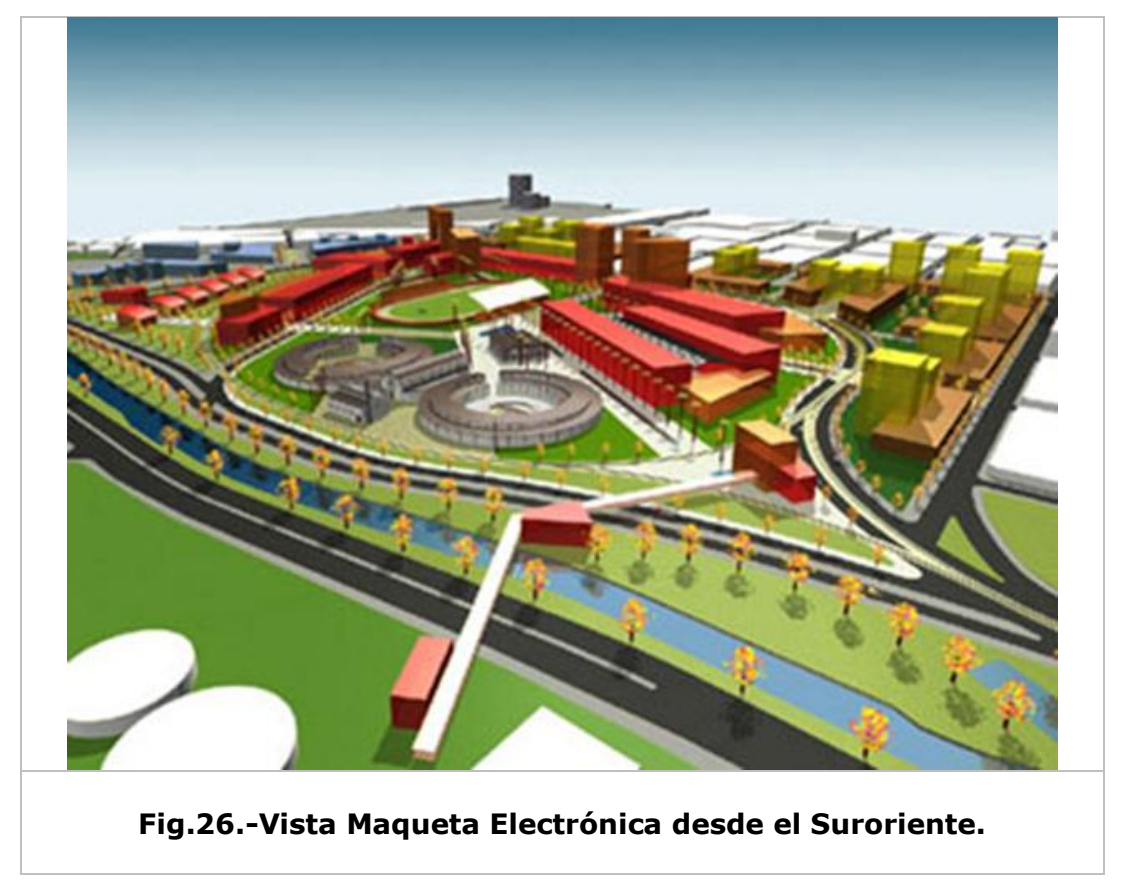

La estrategia territorial se basa en el al desarrollo de macrozonas de alto potencial inmobiliario con usos preferentes, en un caso de vivienda $y$, en el otro caso, de equipamiento, con el propósito de generar una mezcla de usos con alta tasa de ocupación de suelo y maximizar los beneficios en toda el Área de Impacto del proyecto.

Reconociendo la escasez de financiación pública para las inversiones en el predio de la Maestranza, la estrategia de financiación se orienta y procura acciones e inversiones vinculadas al mejoramiento del espacio urbano y la provisión de áreas verdes a través de mecanismos normativos para los emprendimientos inmobiliarios. Para el desarrollo inmobiliario y de la provisión de la obras de urbanización que den suficiencia a las 43 hectáreas del predio, se postula el financiamiento con capitales privados y las alianzas estratégicas entre capitales nacionales e internacionales. Se propone el uso de todos los mecanismos e instrumentos que el Estado, a través de sus diversos organismos, ofrece para materializar inversiones. 


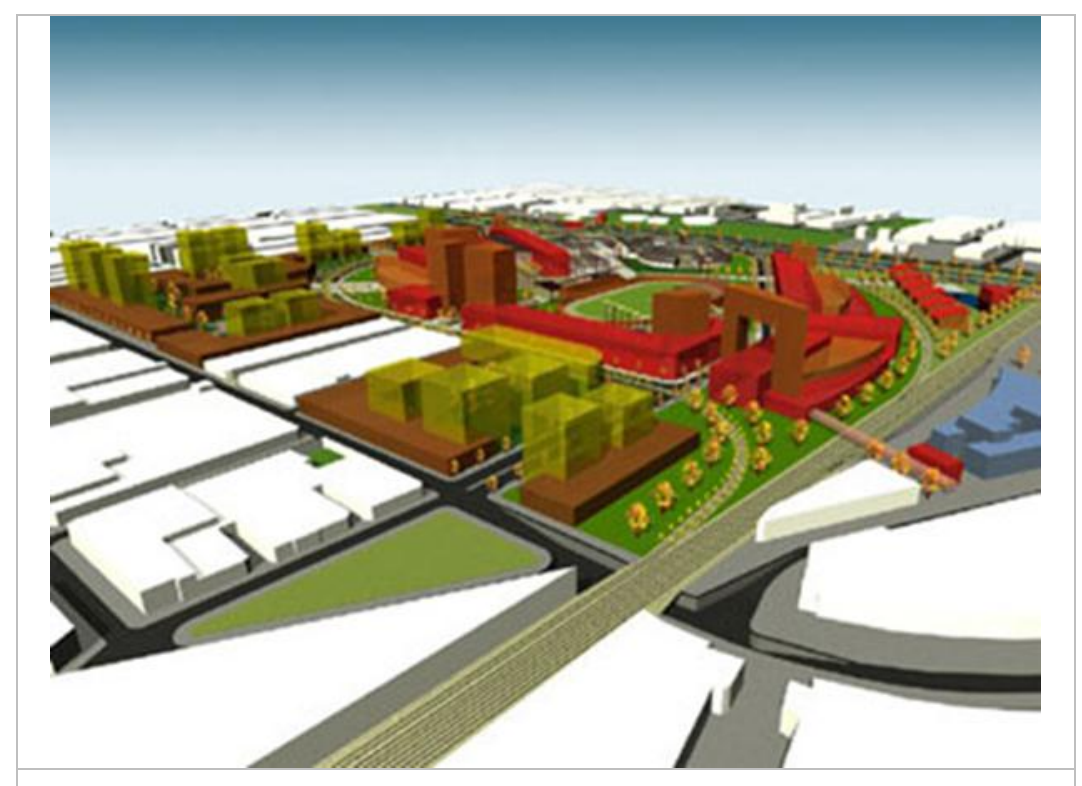

Fig.27.- Vista Maqueta Electrónica desde el Norponiente

Entre los instrumentos del Estado se pueden tener presente: Fondo de Desarrollo e Innovación FDI - CORFO; Fondo de Asistencia Técnica FAT - CORFO; Fondo de Estudios Regionales, FER - CORFO; Proyecto de Fomento Asociativo PROFO, de CORFO y SERCOTEC; Programa Territorial Integrado PTI, CORFO; Programa de Parques Urbanos, SEREMI MINVU; Programas de Vialidad Urbana Estructurante, Programa de Vialidad Intermedia, SEREMI MOPTT; Programa de Renovación Urbana, Subsidio Unificado, SERVIU Metropolitano; Gobierno Regional FNDR; METRO de Santiago.

En cuanto a la estrategia administrativa, se propone la creación de una organización que sea capaz de liderar y llevar adelante el proyecto de reconversión de la Maestranza de San Eugenio. La institucionalidad debe integrar al sector público y al sector privado con un objetivo común.

Se postula una estrategia de posicionamiento y comunicación para el logro del objetivo enunciado precedentemente, para ello se recomienda la creación de un Plan de Difusión que esté basado en diversas herramientas publicitarias y de marketing para difundir el proyecto de reconversión y socializar sus beneficios. 


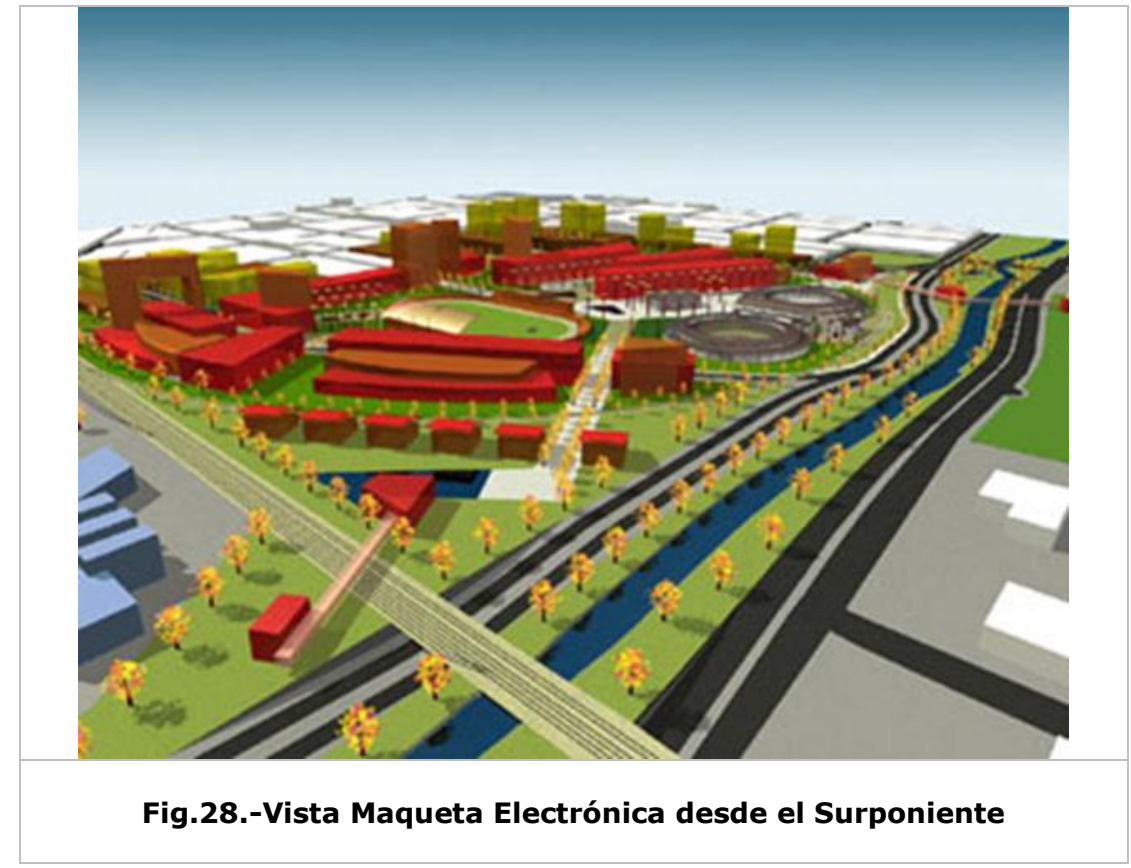

Las estrategias inmobiliarias se basan en una oferta variada que incluye viviendas, oficinas, centros comerciales y equipamiento de educación, salud, deportes y áreas verdes en forma preferente, de manera que la oferta de suelo mejore la competitividad y habitabilidad de la zona. Es decir, se posibilita una oferta inmobiliaria integrada y que considere variables como cantidad, calidad, localización y precio para lograr heterogeneidad formal y social.

Finalmente, las estrategias asociadas a la conservación del patrimonio arquitectónico y urbano como elementos o áreas específicas que permiten hacer presente la memoria histórica e imagen colectiva que refuerza el pasado, permite vivir el presente y nos proyecta al futuro. La orientación reconoce el patrimonio como un concepto integral.

\section{Concurso Internacional de Ideas Av. Vitacura Oriente}

Proyecto presentado por nuestro estudio profesional al Concurso Público convocado por la Municipalidad de Vitacura a inicios del 2006. Está referido a la zona de influencia de Av. Vitacura, en el tramo comprendido entre Gerónimo de Alderete y Tabancura. La superficie diseñada en el proyecto alcanza a las 163 hectáreas.

El proyecto urbano propuesto es la respuesta para fortalecer y re-construir la imagen local de la zona. Considera un horizonte de consolidación entre 10 y 15 años. Conceptualmente se recurre a las raíces del territorio, cuyo paisaje asociado al cordón de cerros del Manquehue (lugar de cóndores), posibilita la reestructuración y ordenamiento del área a partir de la imagen-objetivo de un cóndor (Figura No 29). Se asume como principio considerar la ciudad no como un ensamblaje de edificaciones (aunque éstas sean arquitecturas del más alto nivel), sino como un sistema de valores y resultados de la historia y de la memoria colectiva, legibles, identificables y reproducibles en la sociedad actual con una oportuna mirada de propuesta proyectual. 


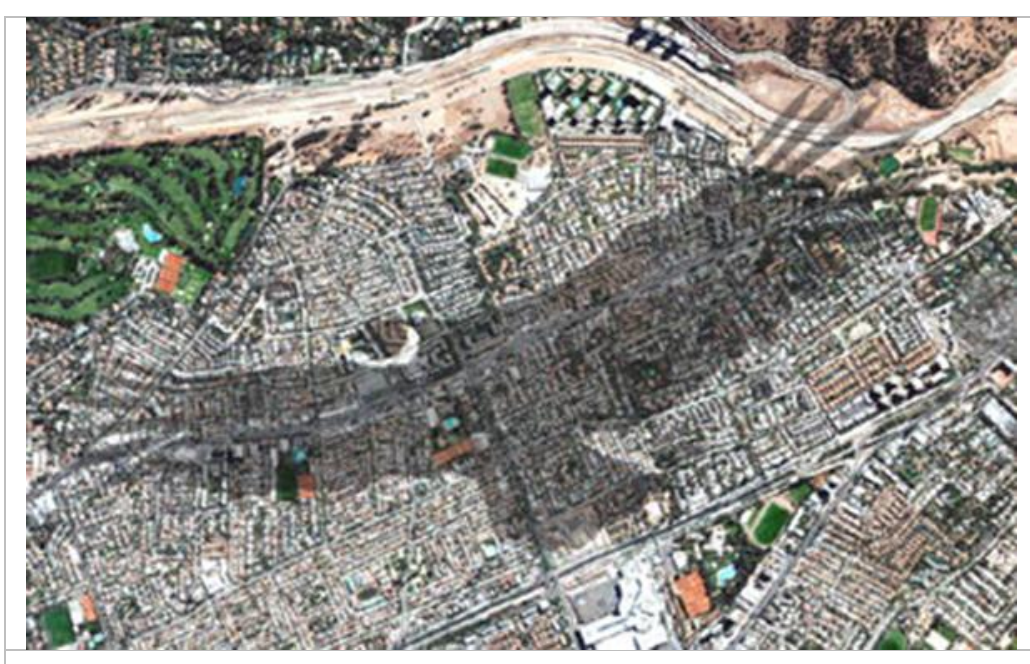

Fig.29.- Imagen - Objetivo Conceptual

Basados en los principios y dimensiones del diseño urbano, se postula un reordenamiento de la trama vial, con un par de vías con sentido único de tránsito, que generan una isla central (proyecto estratégico de primer orden) -de 32,62 hectáreas-, de alta intensidad de uso y escala, que junto al sistema de áreas verdes constituido por los jardines de las áreas residenciales que se conservan, las plazas públicas, los estadios privados y las nuevas áreas libres privadas, semipúblicas y públicas que se proponen, fortalecen la imagen de ciudad jardín de Vitacura y, a su vez, crea lugares, servicios y agrupamientos tales, que por sí mismos serán elementos de gran atracción y demanda, proporcionando un soporte adecuado para estimular la generación de un contexto integrador donde se ejerza ciudadanía.

Se postula la desafección del aumento en el perfil de la Av. Vitacura y construir un par a ella, denominada Av. Liucomohue. Éstas serán vías de servicio y cada una tendrá un sentido de tráfico rodado con tres carriles. El diseño considera aumentar el ancho de las aceras en forma asimétrica, siendo más ancha la acera relacionada a la isla central, incluyendo una ciclovía. Las aceras aumentan al normarse la línea de edificación retirada de la línea oficial, al menos en 6 metros y sin cierros, de modo que el espacio público sea un lugar no sólo para la circulación, sino que también para la detención y la contemplación. 


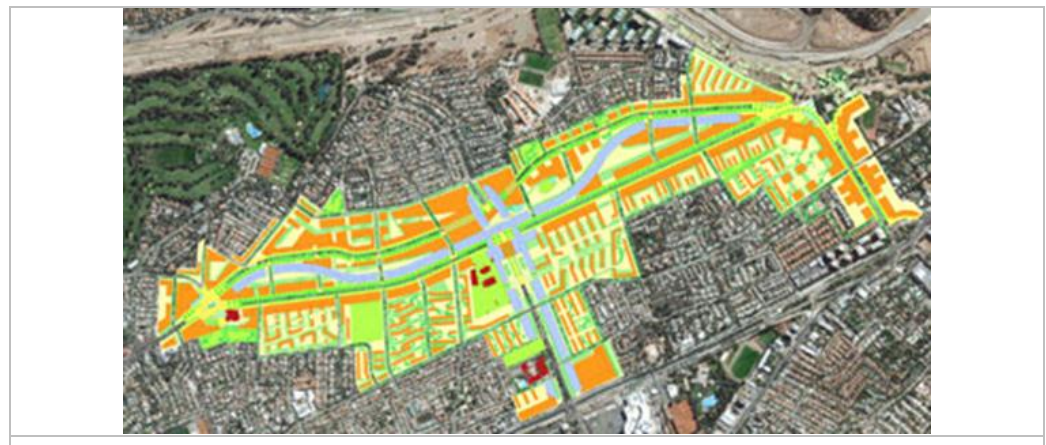

Fig.30.- Plan Maestro de Renovación Urbana Vitacura Oriente

El sistema vial propuesto considera calles exclusivas para peatones. La principal, es la propuesta por el interior de la isla central, a modo de Bulevar, que recoge la tensión oriente-poniente, la cual es cruzada por ocho vías peatonales transversales, posibilitando la conectividad de ésta con el resto de los barrios. Así, se rescata la continuidad de lo público en un ambiente de intimidad.

El proyecto se concibe como un sistema global, integrado y equilibrado entre diseño urbano y gestión urbana, mediante la definición de zonas de diversas escalas o intensidades de uso, que tienen una modelación cuidadosa en pro de la imagenobjetivo. Las edificaciones se proponen con alturas que van entre las 6 y las 30 plantas, ellas vitalizarán los ambientes, mediante transiciones, que consideran la escala general, transformando el recorrido en un viaje a través de una propuesta paisajística (17,8 hectáreas de plazas, parques y estadios) acogedora y atractiva para los diversidad de usos y actores, potenciando la Vitae Urbanae Qualitas.

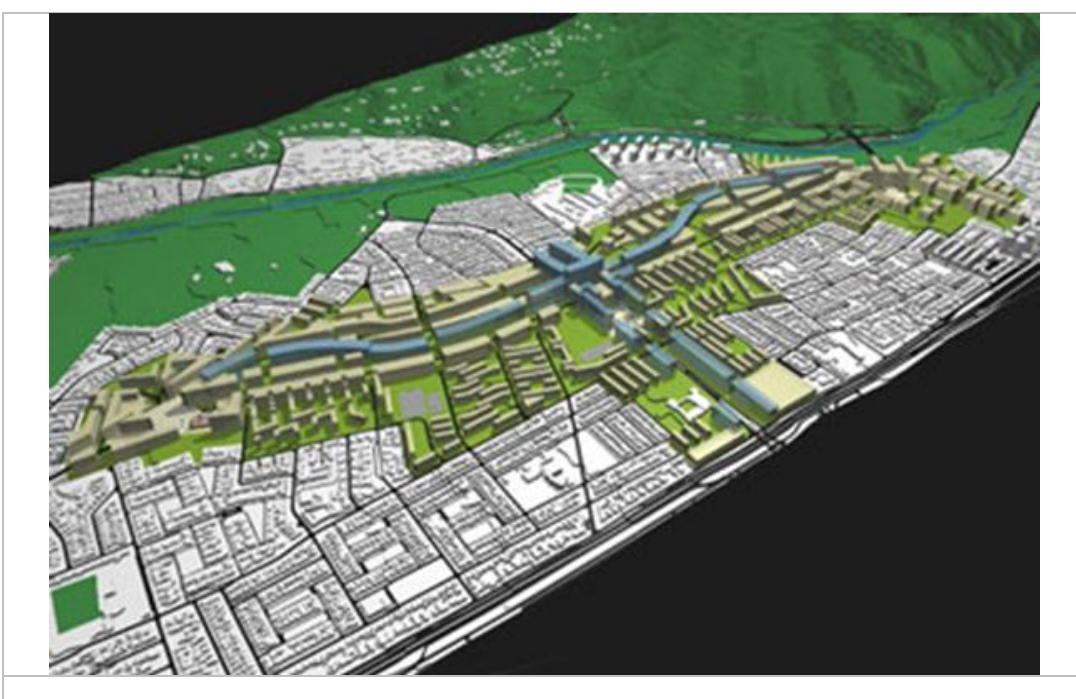

Fig.31.- Vista diurna de maqueta electrónica a Vuelo de Pájaro 
Para materializar la imagen-objetivo y conceptual, se postulan proyectos estratégicos, intervenciones de efecto multiplicador, que permiten proyectar una imagen positiva, capaz de atraer y captar capitales, pues son acciones generadoras de externalidades positivas. Adicionalmente, al Bulevar al interior de la isla central, se conciben tres plazas como proyectos estratégicos prioritarios.

La estructura proyectada recoge la tensión poniente-oriente, pero a la vez, las relaciones y conexiones transversales. La trama, a modo de palimpsesto, contribuye a crear la condición de lugar y organiza los hitos y nodos de las tres Plazas: de Los Castaños; del Padre Hurtado; y, de Tabancura, acentuando la identidad y la imagen de la zona de renovación. A ellas, se agregan las 5 paradas del sistema de transporte público, denominadas estaciones: Los Castaños; Estadio Croata; Padre Hurtado; Casas de Lo Matta; y, Tabancura, unifican las actividades existentes y propuestas.

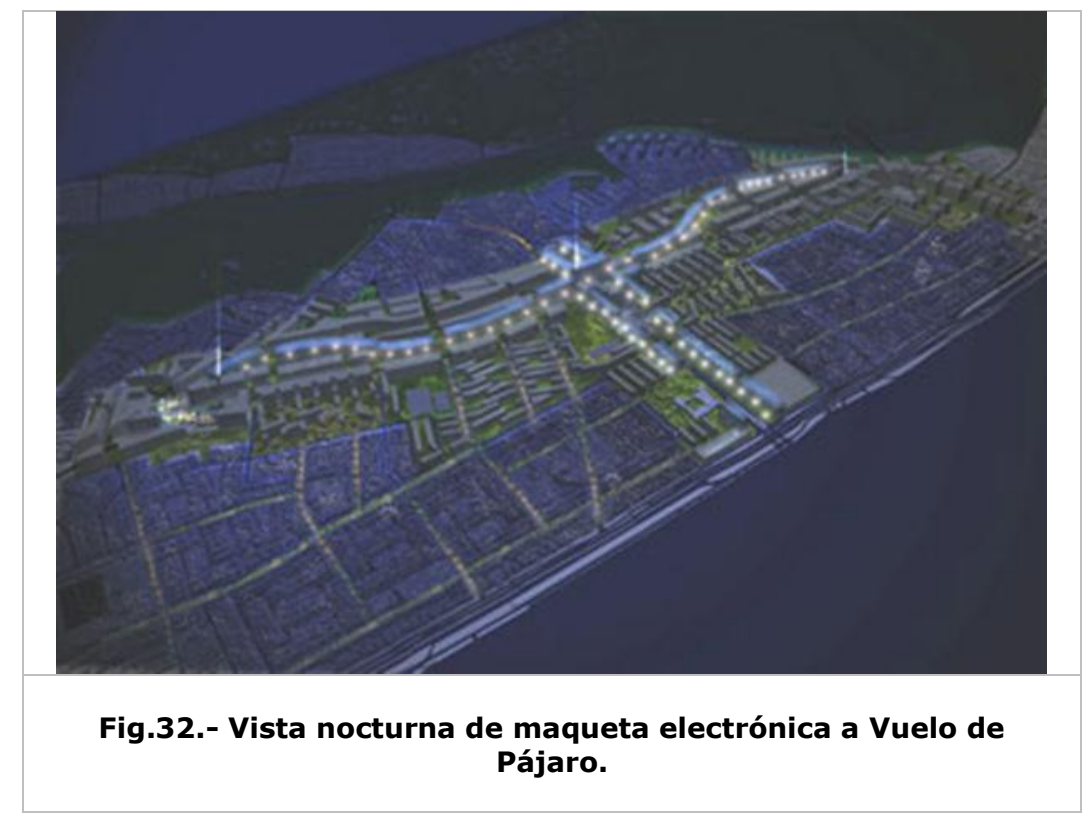

El objetivo de los proyectos estratégicos prioritarios es la integración de la comunidad, de lugares, de actividades, de elementos varios, es decir, buscan construir un lugar, con imagen e identidad propia. Las ciudades son organismos de tramas, algunas tangibles y reconocidas por sus habitantes y otras intangibles. Así, el diseño, propende a la creación de un nuevo lugar, que sea un sello de identidad, con significado y significación que tiende tramas tangibles e intangibles, orientadas a crear diversos tipos de identidad: existencial, empática, conductual, incidental, objetiva y mediática.

El diseño traza, relieves y pliegues, espacios libres y espacios llenos, colores que se entrelazan, texturas, luces y sombras, posibilitando que los elementos vayan emergiendo como personajes de un relato, comprendiendo su totalidad, en su dinámica, armonía, potencia en actividades $y$, de recorridos diversos. En la configuración se utilizan parámetros de diseño relacionados con: claridad, dominancia, intensidad, contraste, extraordinariedad, originalidad, asociatividad, complejidad, direccionamiento, obstáculo, acentuación, gradiente de textura, superposición, clarooscuro, visiones reciprocas, orientación, estimulación, evocación, identidad y estética. 
Estos parámetros de diseño son los principales hilos conductores del relato o de la trama del proyecto.

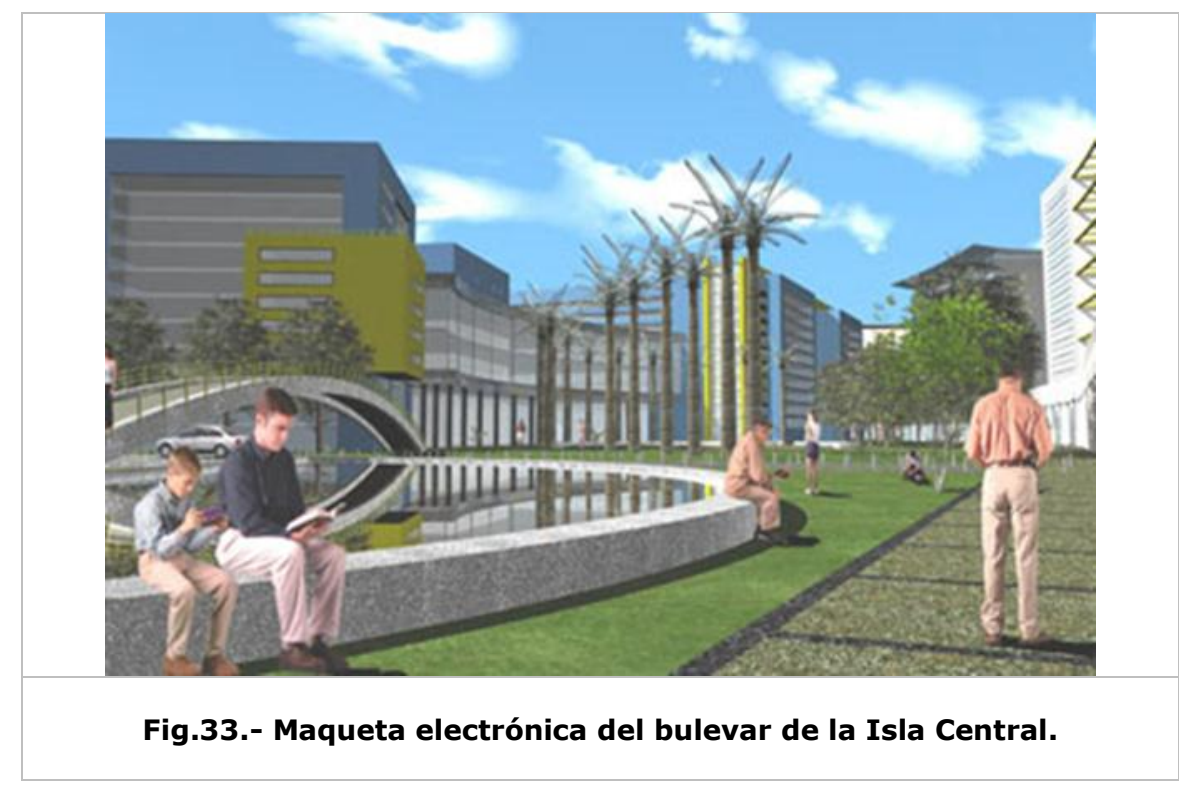

Vitacura Communa: Vitae Urbanae Qualitas, se postula como un lugar de un sinfín de circuitos, formando las redes de relación: del agua; de la vegetación; de senderos peatonales; de muros y pavimentos; de iluminación; de mobiliario urbano; de espacios y edificaciones; de visitantes y usuarios.

Respecto del uso del suelo, la propuesta propende a la diversidad, teniendo mayor presencia el uso residencial. En la isla central y en los bordes de las avenidas Vitacura, Padre Hurtado y Tabancura, y una parte de la acera norte de Av. Liucomohue se establece una zona preferente de equipamiento, pues se desea heterogeneidad, con el propósito de lograr mayor vitalidad en toda el área afecta a intervención. Esta zona se orienta a usos preferentes de equipamiento de escala intercomunal y comunal, con localizaciones residencial en pisos superiores con el fin de potenciar las vistas hacia el cordón de cerros del Manquehue y la Cordillera. 


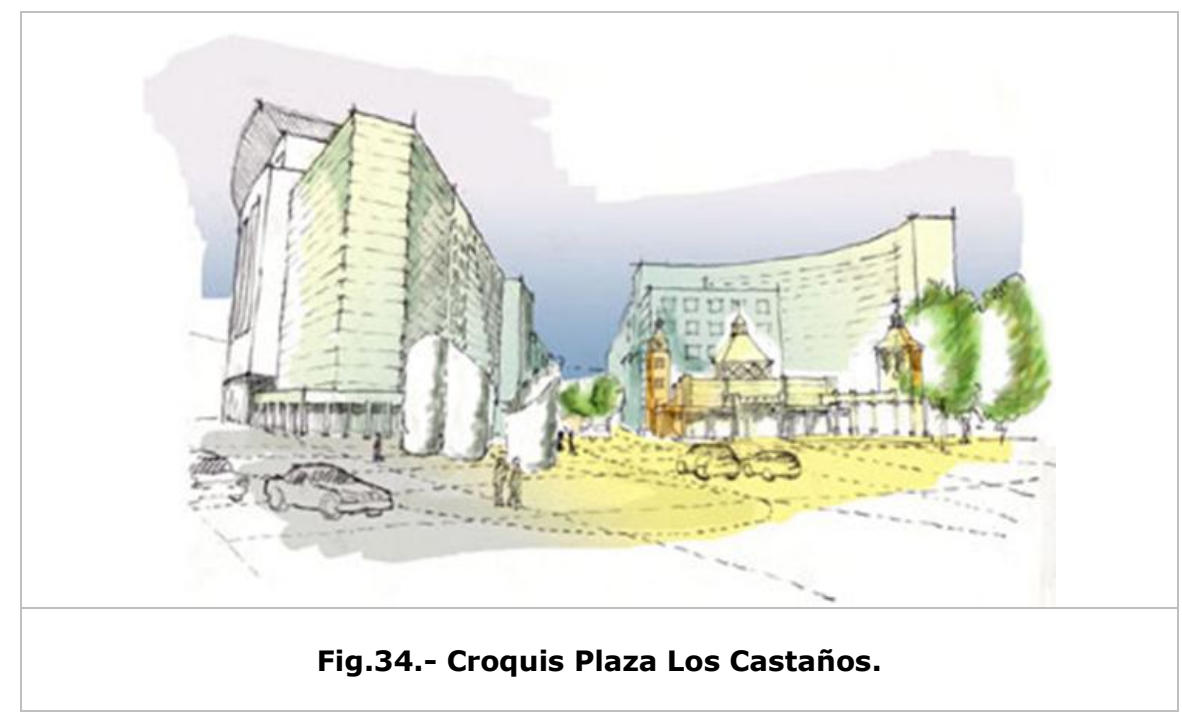

La morfología arquitectónica incorpora sectores con elevaciones o sinuosidades, que rompen la monotonía impuesta por la pendiente base y que permiten acceder, tanto a vistas globales en todas direcciones como al marco de montañas. Se propone una constructibilidad promedio -para el área-de 4,65 y ocupación de suelo promedio de 0,41 . Con un leve aumento en la ocupación del suelo se aumenta en más de cuatro veces la intensidad de uso. La altura mayor que se propone está sobre la acera norte de Av. Vitacura, en el eje de Av. Padre Hurtado, con un edificio que se levanta sobre el espacio público, generando un umbral o puerta en sentido norte-sur. Las mayores alturas se concentran en los tres nodos, siendo el más jerárquico el que corresponde a la plaza Padre Hurtado. La propuesta de altura de las edificaciones está formada por gradientes tanto en sentido norte-sur como oriente-poniente. Las edificaciones de menor altura alcanzan las 6 plantas y las de mayor altura llegan hasta las 30 plantas. Las áreas de 6 plantas se proponen como plataformas de equipamiento comercial en el nodo central de la propuesta. 


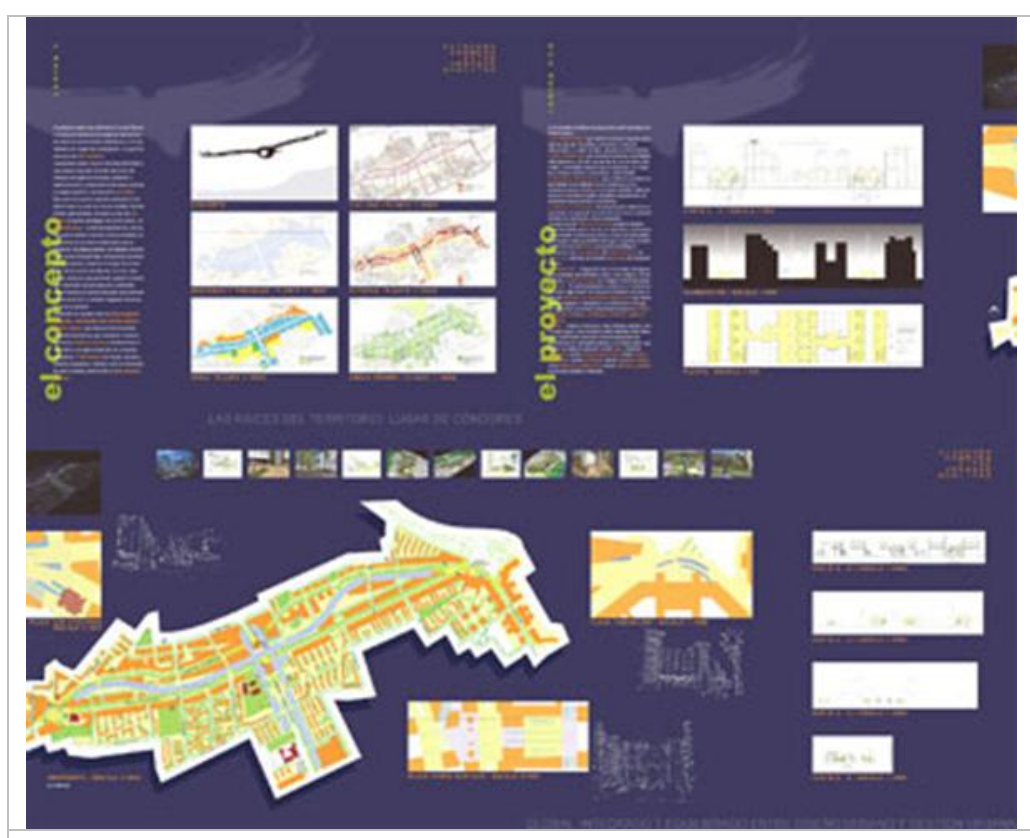

Fig.35.- Presentación al Concurso.

La gestión como herramienta de conducción del proceso de cambio y de su posible evolución, considerando las dinámicas y las actuaciones en marcha, las demandas sociales, los puntos críticos, los obstáculos de las organizaciones y las potencialidades del territorio, define estrategias asociadas al territorio, al financiamiento, a la administración, al posicionamiento y a la comunicación, e inmobiliarias.

\section{Conclusión}

Concebimos todo proyecto urbano u intervención urbana como un compromiso ético, en el sentido más amplio del término, tanto con la sociedad actual como con las futuras, con aquellos no nacidos aún, para quienes el corto plazo es el ayer. Todo proyecto urbano es de largo plazo. Sin embargo, hoy, en la construcción de la ciudad, vemos como la ambición se aferra a la idea de que el largo plazo no existe.

Quizás por ello, los planes presentados pueden parecer -en una primera aproximación- una utopía. Pero, la necesidad de modificar los modos de concebir, de realizar y de gestionar nuestras ciudades, sobre la base de reestructurar los lazos sociales y el cambio de la naturaleza y escala de los desafíos colectivos que se expresan en las grandes metrópolis, dan paso a esta nueva forma de abordar el diseño urbano, visto de manera lejana y carente de factibilidad para llevarse a cabo.

Sin embargo, las propuestas presentadas carecen de ambición en cuanto a los programas formulados y a las masas edificadas, por el contrario, son meras posibilidades dentro de un gama, ellas ofrecen posibles respuestas conceptuales o teorías explicativas, posibles proyectos, e incluso, posibles resultados, todo como parte 
de un proceso, que pretende socializar las mejoras necesarias para una ciudad, que quiere entregar a sus habitantes una mejor calidad de vida.

Por lo anterior, los planes o proyectos urbanos, son al mismo tiempo, un instrumento de análisis, propuesta y negociación. Exploran, investigan e incorporan la diversidad, de forma positiva, en relación con los principios proyectuales explicitados. El urbanismo actual debe privilegiar estos objetivos y los contextos en los que se desenvuelven. Paralelamente, debe concentrar sus esfuerzos en estimular a los actores públicos y privados, para descubrir la rentabilidad económica en la materialización eficaz de tales objetivos en favor de la comunidad.

No es posible dejar de pensar, que la ciudad ha sido, es y será el lugar de la realización plena e integral del hombre. La ciudad es lo más trascendente al hombre, en la inmanencia de la ciudad él busca su trascendencia. Para ello, contamos con el diseño urbano, que posibilita ofertar una adecuada cantidad de bienes públicos, más allá de los índices de constructibilidad, ocupación de suelo o alturas de la edificación. El éxito está asegurado con adecuadas mezclas de actividades y de habitantes, es decir, con la heterogeneidad, tanto espacial como social. Por ello, en estos planes, la gestión urbana se ha mirado desde los principios y dimensiones del diseño urbano.

\section{Bibliografía}

Bentley, Ian et al: Entornos Vitales. Hacia un Diseño Urbano y Arquitectónico más Humano. Manual Práctico. Editorial Gustavo Gili S. A., Barcelona, España, 1999.

Carmona, Matthew et al: Public Places Urban Spaces. The Dimensions of Urban Design. Architectural Press, Oxford, United Kingdom, 2003.

Francis, Mark: Urban Open Space. Designing for User Needs. Landscape Architecture Foundation, Island Press, Washington DC, USA, 2003

López C., José: Diseño Urbano: Teoría y Práctica. Editorial Munilla-Lería, Madrid, España, 1999.

Ministerio de Vivienda, Urbanismo y Bienes Nacionales; Directorio Ejecutivo Obras Bicentenario: Anillo Interior de Santiago: Un Desafío de Gestión Urbana Estratégica. Ministerio de Vivienda, Urbanismo y Bienes Nacionales; Santiago; Chile; 2003.

Ministerio de Vivienda y Urbanismo; Directorio Ejecutivo Obras Bicentenario: Análisis Patrimonial, de Gestión e Inmobiliario Maestranza San Eugenio. Universidad de Chile, Facultad de Arquitectura y Urbanismo; Santiago; Chile; 2004.

Vélez, Antonio (editor): Ideas Urbanas para Santo Domingo 2002. Inmobiliaria BHD y Ayuntamiento del Distrito Nacional; Santo Domingo, República Dominicana; 2002. 


\section{Anexo: Equipos de profesionales por proyecto}

Plan Maestro Villa Mella: Ideas Urbanas Santo Domingo 2002

Mario Torres Jofré, arquitecto

Andrea Woerner Rudloff, arquitecta

Plan Maestro Anillo Interior de Santiago - Segmento D - 2002 Jefe de Equipo

Mario Torres Jofré, arquitecto

Profesionales

Andrea Woerner Rudloff, arquitecta

Carolina Devoto Magofke, ecóloga paisajista

Daniela Pollmann Fleming, diseñadora gráfica

María Eugenia Pallarés Torres, arquitecta

Manuel Fernández Hechenleitner, arquitecto

Felipe Gallardo Gastelo, arquitecto

Pablo Hidalgo Sandoval, arquitecto

Ernesto López Morales, arquitecto

Francisco Martínez Concha, ingeniero civil

Carlos Muñoz Parra, arquitecto

Gustavo Rodríguez Jaques, arquitecto

Juan Sabbagh Pisano, arquitecto

Rubén Salgado Castro, ingeniero civil

Jaime Valenzuela Schoolz, ingeniero civil

Enrique Zárate Campaña, ingeniero de ejecución en meteorología

Plan Maestro Maestranza de San Eugenio - 2004

Jefe de Equipo

Mario Torres Jofré, arquitecto

Profesionales

Andrea Woerner Rudloff, arquitecta

Andrea Ferrer Balart, abogada

María Eugenia Pallarés Torres, arquitecta

Paola Jirón Martínez, bachelor of commerce

Sandra Caquimbo Salazar, arquitecta

Antonio Sahady Villanueva, arquitecto

Enrique Zárate Campaña, ingeniero de ejecución en meteorología

Felipe Gallardo Gastelo, arquitecto

Javier Quintero Zuluaga, arquitecto

Pedro Donoso Sierra, ingeniero civil

Raúl Castellanos Mora, ingeniero civil

Colaboradores

Paula Araya Núñez, Licenciada en Arquitectura

Carolina Oteo Morgan, Licenciada en Arquitectura

Felipe Lanuza Rilling, Arquitecto

Rodrigo Melo Rivora, Arquitecto

Concurso Internacional de Ideas Av. Vitacura Oriente - 2006

Mario Torres Jofré, arquitecto

Dipl. - Ing. Andrea Woerner Rudloff, arquitecta

Javier Quintero Zuluaga, arquitecto

Dr. - Ing. Michael Trieb, arquitecto

Dr. - Ing. Seog - Jeong Lee, arquitecta

Paulina Sir Fierro, arquitecta

Ximena Milosevic Díaz, diseñadora gráfica

Colaboradores

Hernán Cortés Piñones, arquitecto

Gaspar Arenas Acuña, diseñador industrial

Myriam Loy Decebal-Cuza, licenciada en arquitectura

Carol Litin Morales, diseñadora digital 